\title{
Evidência de tensão N-S intraplaca no neógeno, Complexo Atuba - região de Curitiba (PR)
}

\author{
Lilian Chavez-Kus ${ }^{1}$ \& Eduardo Salamuni ${ }^{2}$
}

\begin{abstract}
Resumo No arcabouço estrutural do Complexo Atuba a deformação atual ou pré-atual ocorre em regime rúptil decorrente de falhas recentes ou reativadas segundo um sistema transcorrente dominante. Além das falhas na escala regional que coincidem com reativações dos já existentes alinhamentos NE-SW e NW-SE, foram geradas novas estruturas a partir do Neógeno com característica distensiva e cisalhante concordantes com o vetor de tensão principal $\left(\boldsymbol{\sigma}_{1}\right)$, horizontal e orientado para N-S. Associado às estruturas N-S ocorre um sistema conjugado transcorrente proeminente nas direções N20-35E e N20-35W. As falhas destas famílias são responsáveis pelo deslocamento de diques de diabásio e lamprófiros. O mesmo sistema transcorrente provoca estrias de atrito nos gnaisses, assim como estruturas sub-verticais conjugadas que se estendem na cobertura sedimentar da Bacia de Curitiba. Além do sistema transcorrente ocorrem grandes falhas inversas de baixo mergulho $\left(20^{\circ}\right.$ a $30^{\circ}$ ) nas direções próximas a N20W/35NE e N20E/20NW cujo cisalhamento rúptil gera brecha cataclástica nos gnaisses e deslocamentos em diques. Estas zonas de cisalhamento rúptil estão seccionadas pelos planos associados ao sistema transcorrente antes mencionado. Tal estruturação e sua cinemática permitem caracterizar melhor o evento D2' de Salamuni (1998), cujo campo de tensão atual ou pré-atual apresenta a tensão principal $\sigma_{1}$ na direção N-S. Em termos cronológicos o posicionamento proposto para o campo tensão, caracteriza ciclos ou episódios transtensivos decorrentes de deformações secundárias do regime compressional D2 quando $\boldsymbol{\sigma}_{1}$ anteriormente posicionado aproximadamente na direção E-W passa a orientar-se, pelo menos episodicamente, a partir do fim do Pleistoceno na direção NNW-SSE ou N-S.
\end{abstract}

Palavras-chave: Complexo Atuba, sistemas de falhas, campo de tensão, morfotectônica, morfoestruturas, tectônica recente, hidrogeologia.

\begin{abstract}
Evidence of $N-S$ intraplate stress in the neogene of the Atuba Complex, Curitiba region. In the structural framework of the Atuba Complex, the current or recent deformation is in the brittle regime due recent or reactivated faults in a dominant strike-slip system. Aside from the master faults at the regional scale that already coincide with reactivations of existing NE-SW and NW-SE alignments, new structures were generated starting in the Neogene with extensional and shear characteristics (hybrid) that agree with the maximum compressive stress $(\sigma 1)$ direction in the horizontal. These are also oriented N-S. Associated with the $\mathrm{N}-\mathrm{S}$ structures, a prominent conjugate strike-slip system oriented N20-35E and N20-35W can be found. The shear fractures of these three families are responsible for the displacement and intense fracturing of diabase and lamproites dikes. The same strike-slip system causes slikensides and steps in the gneisses and metabasic rocks, as well as sub-vertical conjugate fractures that extend out into the sedimentary cover of the Curitiba Basin. Besides the strike-slip system, major shallowly-dipping $\left(20^{\circ}\right.$ to $\left.30^{\circ}\right)$ reverse faults exist, oriented close to N20W/35NE and N20E/20NW; their brittle shear generates cataclastic breccia in the gneisses and displacement in diabase dikes. The brittle low-angle shear zones are cut by the strike-slip system mentioned earlier. Such structuring and kinematics allow us to better characterize the D2' event of Salamuni (1998), whose current or recent stress field presents a main $\sigma 1$ in the N-S direction.
\end{abstract}

Keywords: Atuba Complex, fault system, stress field, morphotectonic, morphostructures, recent tectonic, hydrogeology.

INTRODUÇÃO Tensões intra-placa são as direções resultantes de stress do processo de compressão generalizada a que está submetida à Placa Sul-americana pelo seu deslocamento distribuído pela crosta continental com desvios em função de desvios reológicos naturais - problemas de composição de crosta e questões morfológicas de grande escala, por exemplo, a Serra do
Mar. Os locais e manifestação ocorrem onde há fragilidades naturais suscetíveis por estarem em direções favoráveis, como alinhamentos estruturais prévios, tipo Sistema Lancinha e estruturas ligadas ao Arco de Ponta Grossa. Quanto às estruturas geradas, no Brasil pode ser citado todo o sistema de falhas das bacias marginais; as falhas E-W ativas do nordeste brasileiro; o sistema

1 - Bavarian Environment Agency, Department 10, Geological Survey, Unit 104 - Hydrogeology, Germany.

E-mail: lilian.chavez-kus@1fu.bayern.de

2 - Departamento de Geologia, Universidade Federal do Paraná, Curitiba (PR), Brasil. E-mail: salamuni@ufpr.br 
Rifte da Serra do Mar e o sistema de falhas atuais na região amazônica (Hasui 1990, Riccomini \& Assumpção 1999). Dentro deste contexto o presente trabalho traz uma nova contribuição para a discussão sobre a tectônica cenozóica, com base em novas descobertas na região de Curitiba. Estruturas norte-sul e falhas transcorrentes de direção NE-SW e NW-SE formam um sistema conjugado indicando a reorientação do campo local de tensões em função da atuação de tensão N-S intraplaca no Neógeno, no Complexo Atuba.

O Complexo Atuba é um bloco tectônico da Província da Serra da Mantiqueira onde se insere o Domínio Curitiba, estando limitado a noroeste pelas seqüências proterozóicas metassedimentares do Grupo Açungui e Complexo Setuva e a sudeste com os gnaisses granulíticos do Domínio Luis Alves (Fuck et al, 1967; Basei et al., 1992; Siga JR. et al., 1995; Salamuni, 1998). A tectônica pós cretácico que o afetou está ligada a regimes frágeis, ligados a reativação de falhas transcorrentes e à geração de novas estuturas, todas ligadas a processos intra-placa, ou seja, condicionados à tensão principal com $\sigma_{1}$ em geral na posição E-W ou WNW-ESE, em função do movimento da Placa Sul-americana. O regime em geral é compressional ou transpressional, (ver discussões em Zoback, 1992 e Assumpção, 1992). Todavia, a alternância de posição de $\sigma_{1}$ é deduzida pelo fato de haver alívio e distensão que fizeram com que o regime distensivo estivesse ativo. Na região estudada, Salamuni (op cit.) e Salamuni et. al. (2003) interpretaram que, entre o Oligoceno e o Mioceno estiveram ativas as falhas normais quando o tensor principal $\sigma_{1}$ esteve posicionado na vertical (Fig. 1). Ainda segundo interpretação dos citados autores, houve mudança na posição dos tensores a partir de eventos tectônicos, que chamaram de D2/D2'. Em D2, $\sigma 1$ passou a atuar na horizontal em um regime compressional/transpressional na direção variando de E-W até WNW-ESE associado a um tensor mínimo $(\sigma 3)$ na horizontal e direcionado para N-S. Nesta situação, fa-
Falhas Normais

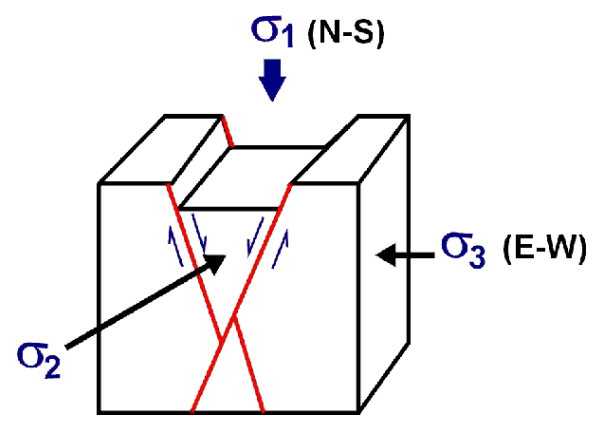

Figura 1 - Fase D1: tensor principal $\sigma_{1}$ esteve posicionado na vertical.

lhas transcorrentes e inversas passaram a ser responsáveis pelo alívio de tensões a partir do fim do Plioceno e início do Pleistoceno (Fig. 2A e 2B). No evento tectônico D2', a tensão principal passar a estar posicionada para NNW-SSE (Fig. 3A e 3B) em um arranjo quase que perpendicular às extensas estruturas transcorrentes geradas em eventos geológicos anteriores, desde o fim do Neoproterozóico (Salamuni et. al., op cit.).

Desde o início das pesquisas referentes à tectônica cenozóica na região, já havia sido observado um conjunto interessante de alinhamentos estruturais de direção N-S, que inclusive condicionam importantes feições geomorfológicas locais. Este padrão estrutural é pouco mencionado na bibliografia em função de ser notório em apenas alguns locais, possivelmente por alguma suscetibilidade reológica da crosta ainda não esclarecida. Todavia, na região central amazônica, no nordeste e na Bacia do Paraná (região de Marília e Cerqueira César-Avaré), também foram descritos movimentos transcorrentes associados a tensões compressionais N-S (Stefanick e Jurdy 1992, Assumpção op

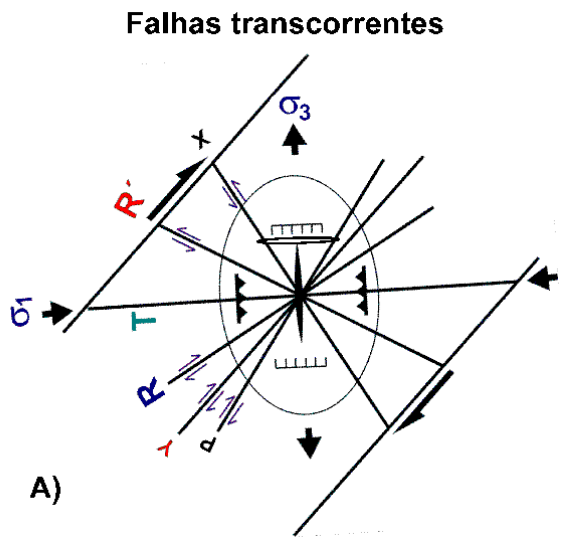

Falhas inversas

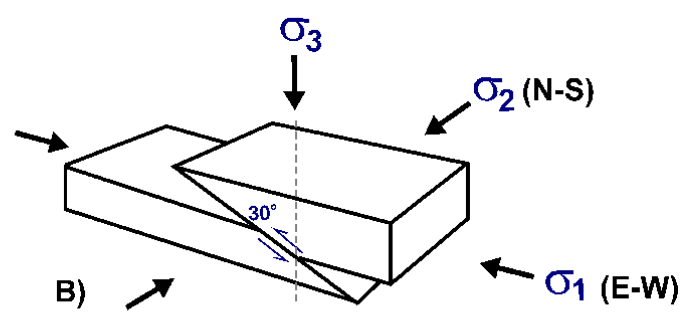

Figura 2 - Posição dos tensores durante a fase D2 (Mioceno): a) o1 passou a atuar na horizontal (falhas transcorrentes) em um regime compressional/transpressional na direção variando de $E-W$ até $W N W$-ESE associado a um tensor mínimo ( $\sigma 3)$ na horizontal e direcionado para $N-S$. b) Ciclo tectônico intermediário entre os eventos D2 e D2': Falhas inversas indicam uma progressividade da tectônica compressiva devido a uma possível rotação dos blocos. 


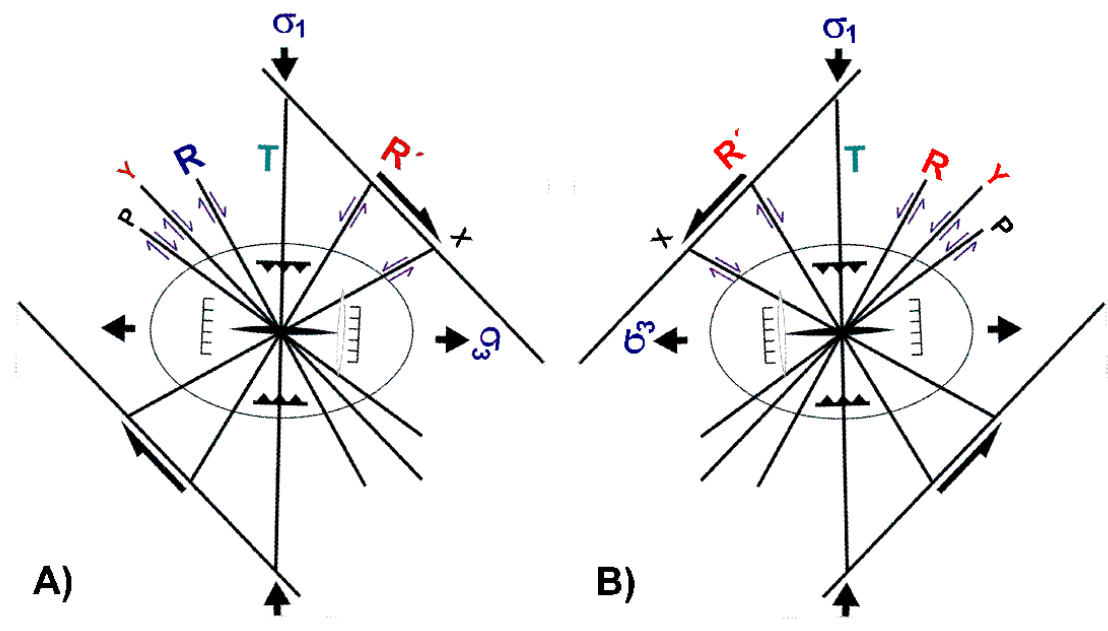

Figura 3 - Arranjo dos tensores a partir do Neógeno (fase D2') tendo por base a análise de drenagens de primeira ordem, ou seja, as mais recentes da Bacia de Curitiba. Nesta situação dois ajustes distintos foram propostos pelo autor onde o $\sigma 1$ direcionado anteriormente a $E$ - $W$ passa a orientar-se mais para NNW-SSE: (a) Binário dextrógiro com compressão N-S; (b) Binário sinistrógiro com compressão N-S.

cit. e Riccomini 1995, 1997). Embora todo continente sul-americano encontre-se sob tensão, a alternância nos esforços pode ser explicada por fases de alívio da placa resultando ora no posicionamento do $\sigma_{1}$ a N-S, ora $\sigma_{1}$ na direção E-W, sendo esta última, em geral, a direção de compressão dominante. Regionalmente ou localmente há mudanças na direção da compressão, a exemplo do que tem sido registrado na região de Curitiba.

Para Zoback (1992) os campos de esforços de primeira ordem no interior das placas são gerados em grande parte por forças compressivas aplicadas nas bordas, devido à expansão do assoalho oceânico e pela colisão continental. Porém esforços de segunda ordem, resultado de contrastes laterais de resistência, densidade e forças ascensionais, bem como flexurais, podem até se superimpor aos de primeira ordem. Como o campo de esforços de primeira ordem não atua de forma homogênea nas áreas de escudos e porções crustais mais antigas, os efeitos locais podem prevalescer. Em outras palavras, a grande heterogeneidade e anisotropia da litosfera induzem localmente a dispersões e variações de magnitude nas direções dos tensores.

Lima (1999) menciona que reajustes decorrentes de tensões laterais vêm ocorrendo a partir do Cenozóico e o mecanismo de rotação da posição dos tensores pode ser resposta à ação de forças contrárias vindas do movimento das placas Nazca e Cocos que passaram a atuar, a partir do Neógeno, contra a direção de separação entre as placas Sul-americana e a Africana (Ricomini et al., 1989).

Nas análises de Salamuni (op cit.) e Salamuni et al. (2004) foram reconhecidos na Bacia de Curitiba, cujo embasamento é o Complexo Atuba, terraços e depósitos aluvionares disseminados e não contínuos, horizontes lateríticos truncados, camadas sedimentares posicionadas em cotas diferentes, captura e anomalias de drenagens sendo estas feições de grande importância e atribuídas à falhas recentes. Estas informações aliadas a análise estrutural, morfoestrutural e de lineamentos, em dados estruturais do embasamento e sedimentos da bacia, corroboram o modelo estrutural proposto para os arranjos dos campos de tensão a partir do Neógeno onde novos eventos tectônicos foram e, talvez continuem sendo, responsáveis pela esculturação da região até o Recente

O Complexo Atuba (Siga JR et al., op cit.) ocorre no município de Curitiba e regiões circunvizinhas do Primeiro Planalto Paranaense e anteriormente recebia nomes regionais como Complexo Costeiro ou simplesmente uma denominação genérica como "Embasamento Cristalino". Nesta unidade, formada no Paleoproterozóico e intensamente retrabalhadas no Neoproterozóico e Eopaleozóico, predominam gnáisses bandados e granitóides em parte migmatizados. Os litotipos são representados principalmente por biotita-anfibólio-gnaisse, podendo ser subdividido em (a) gnaisse bandado contendo leucossoma de composição tonalitogranodiorítica e melanossoma rico em biotita-anfibólio e (b) gnaisse granítico bandado com pouca biotita (Basei et al., op cit.; Siga JR et al., op. cit.). Ocorrem ainda paragnaisses, quartzitos de granulação variada, quartzo xistos, micaxistos, anfibolitos, gnaisses-granitos e ainda granulitos (Bigarella e Salamuni, 1959; Fuck et al. op cit.; Batola JR. et al., 1981). Diques de rochas básica e intermediárias com direção principal NW-SE, de idade Jurássica à Cretácea, completam o conjunto que compõem os litotipos desta unidade, cuja síntese é descrita no quadro 1. Em termos metamórficos, as rochas do Complexo Atuba apresentam paragênese de grau metamórfico médio a alto (fácies anfibolito), com cristalização de granada, hornblenda e biotita. A presença de recristalização de muscovita, biotita derivada 


\section{Quadro 1 - Sintese dos litotipos do Complexo Atuba (mod. Salamuni, 1998).}

metabasitos anfibolitos e metaultrabasitos
corpos gnaissicos-graníticos
Gnaisses indiferenciados migmatizados
subordinadamente xistos, quartzitos finos e supostos paragnaisses com quartzo-feldspatos diferenciados
$\begin{aligned} & \text { corpos graníticos anatéticos, assim como granitos alcalinos a sub-alcalinos da Serra do Mar, entremeados } \\ & \text { por xistos, gnaisses e granulitos } \\ & \text { remobilizações róseas, quartzo-feldspáticas, pegmatitos de natureza discordante e corpos graníticos } \\ & \text { maiores anatéticos }\end{aligned}$

de horneblenda e quartzo de segunda geração seriam indicativos de uma história de retrametamorfismo até a fácies xisto-verde, zona da biotita, e/ou até mesmo zona da clorita (Basei et al, op.cit; Salamuni, op.cit).

Como caracteres estruturais mais marcantes ocorrem planos de foliação Sn com mergulhos geralmente altos originados por cisalhamento simples dúctil com características de foliação de transposição. Estas estruturas estão orientadas segundo ENE, N10E e EW e ainda alternando-se entre as direções N20W a N40W. Eventualmente também pode ser verificada uma superfície anterior (Sn-1) pouco preservada sobre as rochas e com mergulho de baixo ângulo em relação à Sn. Falhas transcorrentes de caráter rúptil a rúptil dúctil, direção NE-SW, subparalelas à superfície $\mathrm{Sn}$, são observadas em nível de afloramento. São praticamente paralelas às foliações, podendo as mascarar. Isso sugere que em uma fase posterior à justaposição dos terrenos, eventos transcorrentes proterozóicos foram responsáveis prováveis pela superimposição de uma deformação mais rúptil.

Superimposta a esta estruturação dúctil e rúptildúctil, encontram-se estruturas ligadas à tectônica frágil cenozóica. É representada por um sistema penetrativo de falhas e juntas na escala regional, demarcado por grandes e médios alinhamentos estruturais com diversas direções, em parte reativando os já existentes alinhamentos NESW e NW-SE, tais como as falhas do Sistema LancinhaCubatão e estruturas ligadas ao Arco de Ponta Grossa, mas também gerando novas estruturas, principalmente os sistemas direcionados aproximadamente para norte-sul (N-S). Diques de diabásio e corpos intrusivos alcalinos deslocados, assim como fraturas nos sedimentos da Bacia de Curitiba são evidências que corroboram a atuação da deformação rúptil presente no paleógeno e neógeno. Os sedimentos da Bacia de Curitiba, por sua vez, sotopostos ao Complexo Atuba, tem idade oligo-miocênica (ver Salamuni, op. cit) e são representados pela Formação Guabirotuba, pela Formação Tinguis, formada pelo próprio retrabalhamento da Formação Guabirotuba, e pelos depósitos aluvionares recentes.

Em escala local observa-se que as rochas do Complexo Atuba encontram-se, por vezes, bastante cataclasadas, com padrões complexos de fraturamento que só podem ser corretamente delineados por meio de análise da estatística gráfica em estereograma. Lateralmente o Complexo Atuba se estende muito além do município de
Curitiba como é mostrado na área em cinza da figura 4.

Assim sendo a análise morfoestrutural e de lineamentos partiu da escala de observação regional (Fig. 4A), aproximando-se até a escala de observação em detalhe, na qual buscou-se dados para caracterizar com maior precisão as estruturas de grande porte e demais feições morfotectônicas responsáveis pelo arcabouço estrutural geral (Fig. 4B). O objetivo principal é o de mostrar que as estruturação N-S está ligada a um processo tectônico importante, pelo menos do ponto de vista na região em estudo, e que isto é comprovado pela análise estrutural de dados coletados em diversos afloramentos da área analisada.

CONSIDERAÇÕES GERAIS Para o entendimento do modelo estrutural apresentado ressalta-se que as fraturas em geral não ocorrem de forma randômica, mas segundo um padrão geométrico espacial, ligadas às tensões cisalhantes principais. Burbank e Anderson (2001) afirmam ocorrer previsibilidade na geometria das estruturas que afetam as rochas superficiais, drenagens e depósitos de aluviões em resposta ao campo de tensões representado pelo elipsóide de tensões em modelos teóricos de cisalhamento rúptil, tais como o modelo de Riedel (1929), que pode apresentar variação angular entre $30^{\circ}$ até $90^{\circ}$ entre o ângulo do plano " $\mathrm{Y}$ " e das fraturas " $\mathrm{T}$ " (de tensão ou "tip cracks"). Na direção de "T" não são observados planos estriados ou outros indícios de movimento em condições normais de stress (Tschalenko e Ambraseys, 1970; Wilcox, 1973; Petit, 1987), porém com aumento da tensão, pode haver evolução progressiva das fraturas "T" para fraturas do tipo "R". Gamond (1983) discute esta questão, admitindo movimento relativo importante na direção " $\mathrm{T}$ ", quando há indução pela fricção dos planos adjacentes com ângulo próximo ao das fraturas R'.

Segundo Kim et al. (2001) as fraturas "T" ocorrem em ângulos de $30^{\circ}$ até $60^{\circ}$ em relação à falha principal devido a variações nas condições de tensão e reativações, que por sua vez, podem originar fraturas com característica distensiva e cisalhante: híbridas (Bilham e King, 1989; McGrath e Davidson, 1995; Willense e Pollard, 1998). A variação no ângulo entre fraturas "tip cracks" e a falha principal depende de propriedades reológicas da rocha, condições de stress e geometria da superfície da falha, além de a situações envolvendo transpressão ou transtensão, ou ainda, pela variação 
(A)

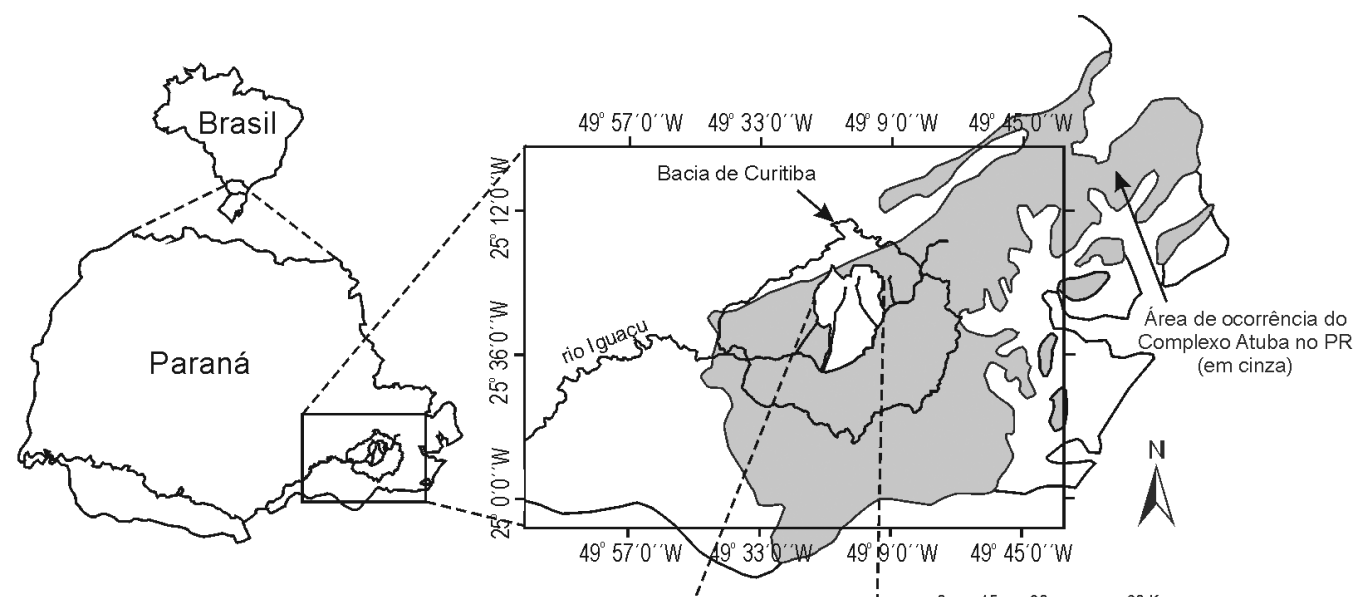

10 - Pedreira Marc 11 - Parque Tingui

2 - Pedreira Maringa

3 - Pedreira Inecol

4 - Pedreira Pussoli

5 - Pedreira Cesbe

6 - Pedreira Transembra

7 - Cascatinha

8 - Pedreira Tanguá

9 - Afloramentos do CIC
12 - Pedreira P. Leminsky

13 - Pedreira Greca

14 - Pedreira Atuba

15 - Boa Vista

16 - Guabirotuba

17 - Guabirotuba

18 - Guabirotuba

19 - Guabirotuba

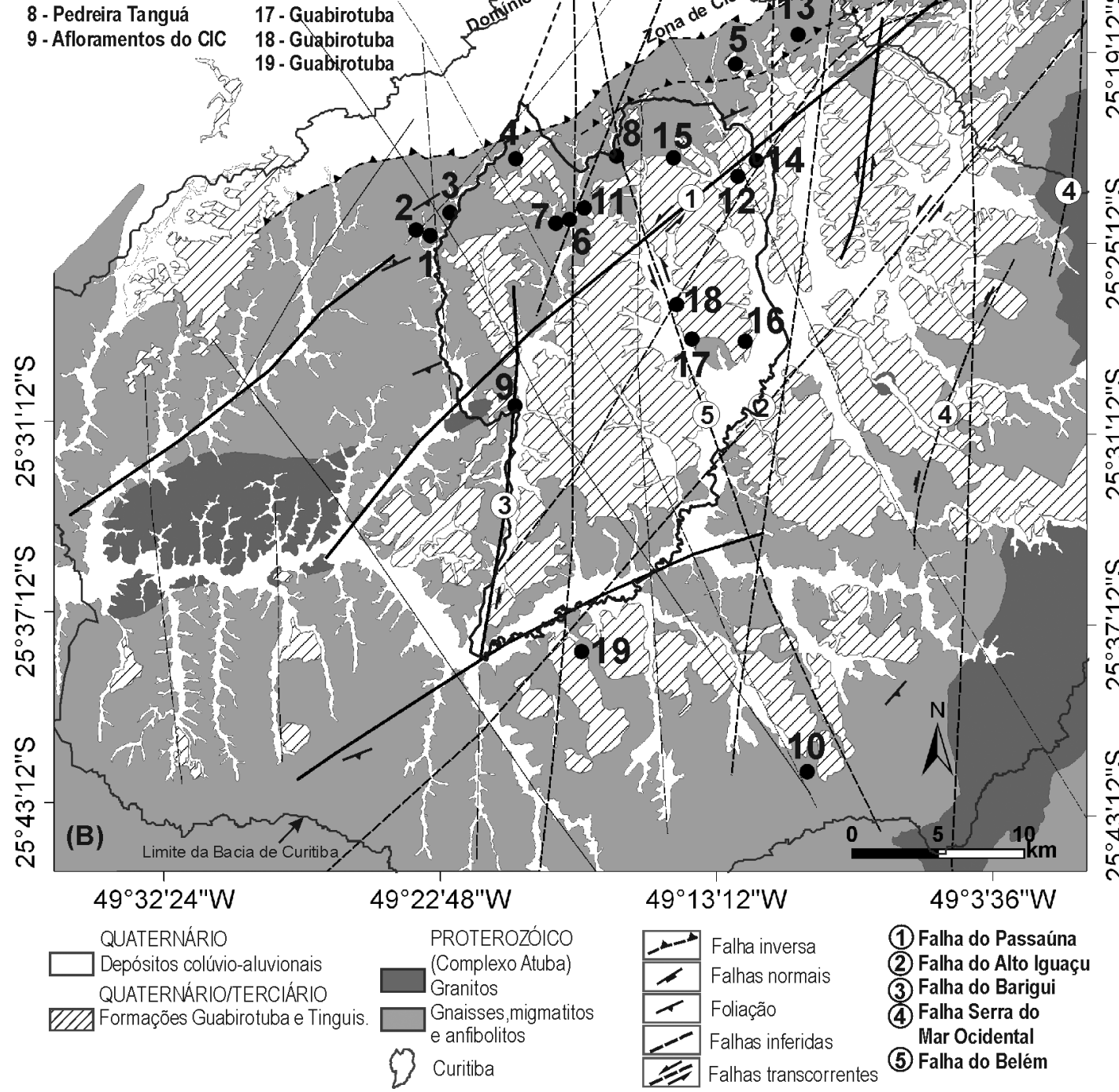

493'36"W

兴

$\stackrel{\infty}{\sim}$

$\infty$

$\stackrel{\frac{2}{2}}{\stackrel{2}{N}}$

m

ก

交

$\stackrel{\infty}{\sim}$

$\infty$

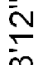

Figura 4 - Localização da área de pesquisa. (A) Principais manchas de ocorrência em Curitiba e municípios circunvizinhos do Complexo Atuba. (B) Os círculos em negro indicam a localização das pedreiras estudadas nesta pesquisa (mod. de Salamuni 2004). Também são vistas as principais estruturas que controlam os principais limites entre os blocos estruturais do Complexo Atuba, no embasamento da Bacia de Curitiba. 
interna da pressão de fluidos e deslocamento originado pela fricção com os planos adjacentes. No modelo de Moody e Hill (1956) associado às falhas mestras (planos equivalentes a "R" e "R'“de Riedel, op. cit.), ocorrem estruturas de segunda e terceira ordem (Fig. 5) antitéticas. Price (1968) e Price et al. (1990) associam a origem destes planos a variações na geometria das paredes das fraturas de primeira ordem e a modificações locais no campo de tensão.

Na classificação genética das fraturas apresentada por Singhal e Gupta (1999) tendo como base o modelo de Ruhland (1973), os planos também são classificados em $1^{\circ}, 2^{\circ}$ e $3^{\circ}$ ordem e os mesmos podem ser do seguinte tipo:

Fraturas de cisalhamento Podem exibir movimento relativo no plano de falha e geralmente configuram sets conjugados com ângulo diedral entre as fraturas superior a $45^{\circ}$.

Fraturas de dilatação São de origem distensiva (abertas) e desenvolvem-se paralelas à direção de tensão principal sem evidência de movimento (fraturas " $\mathrm{T}$ " de Riedel).

Fraturas híbridas Exibem características tanto de cisalhamento quanto dilatacional. Os planos ocorrem formando sets conjugados com ângulo inferior a $45^{\circ}$, são abertos, podem estar preenchidos por veios e apresentar movimento relativo na direção paralela ao cisalhamento principal (ver Fig. 6A). O modelo de Ruhland (op. cit.) ilustra o arranjo dos planos das fraturas de $1^{\circ}, 2^{\circ}$ e $3^{\circ}$ ordens e indica em diagrama de rosetas o intervalo em que as fraturas cisalhantes e de tensão podem ocorrer, conforme as três ordens citadas (Fig. 6B).

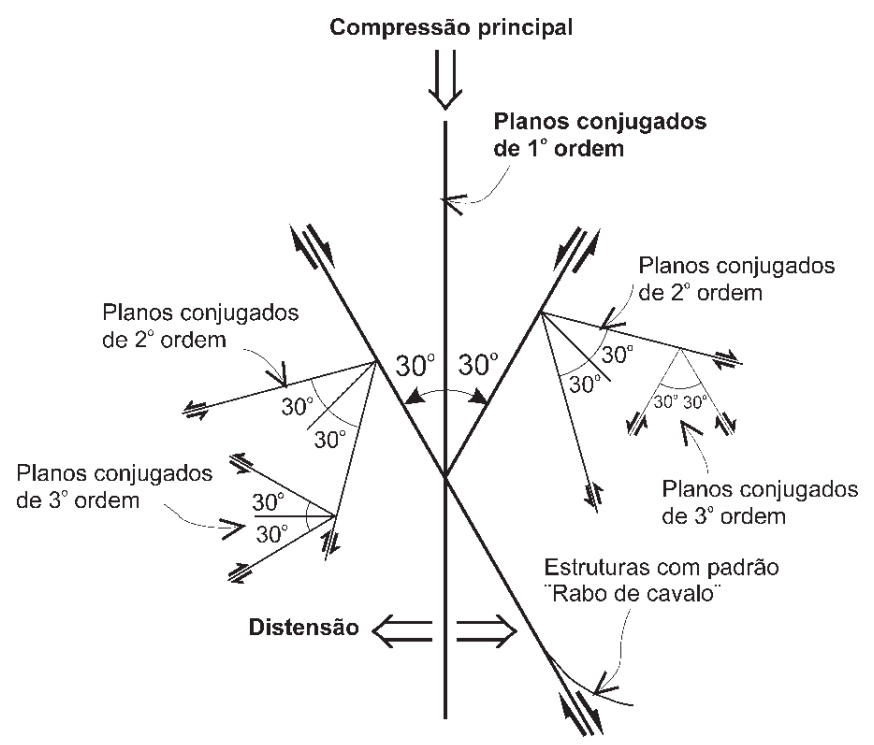

Figura 5 - Modelo com arranjo dos planos das fraturas de $1^{\circ}, 2^{\circ}$ e $3^{\circ}$ ordens (mod. Moody e Hill 1956).
ARCABOUCO ESTRUTURAL LOCAL Embora as rochas do Complexo Atuba sejam condicionadas pela superposição de mais de um evento tectônico, as características estruturais indicam que a deformação atual ocorre em regime rúptil decorrente de falhas recentes ou reativadas segundo um sistema transcorrente dominante. Há uma complexidade estrutural, levando a análise geométrica a priorizar as fraturas mais representativas que geram padrão sistemático e/ou conjugado. Embora ocorram diferentes modas, dentre todas as fraturas observadas em campo, as estruturas N-S estão presentes em praticamente todos os afloramentos observados, considerando-se as estruturas entre N10W a N10E como pertencentes ao mesmo sistema, já que suas características são muito similares. Neste conjunto de famílias verificam-se grandes planos estruturais sub-verticais que apresentam, com freqüência, padrão amendoado e, por vezes, preenchidos por ultracataclasitos ou óxidos. Em outras situações as paredes destas estruturas são caracterizadas por planos verticais abertos, sem preenchimento ou indícios de movimentação (fraturas de extensão).

Associado às estruturas $\mathrm{N}-\mathrm{S}$ ocorre um sistema conjugado transcorrente proeminente formado por fraturas sub-verticais de grande porte em geral com padrão escalonado nas direções N20-35E (predominam falhas com movimentação sinistrógira) e N20-35W (maior freqüência de falhas dextrógiras). A geometria conjugada em forma de "X" é uma das características principais destas famílias, cujo sistema de fraturas cisalhantes é responsável pelo deslocamento e intenso fraturamento de diques de diabásio de grande porte (até $18 \mathrm{~m}$ de largura), havendo registros em um dos afloramentos (pedreira Inecol, ponto 03) de rejeito dextrógiro de $7 \mathrm{~m}$ (Fig. 7). Pequenos e grandes diques, fraturados e movimentados por falhas foram observados na antiga pedreira do parque Tanguá afloramento 08) e também nas pedreiras Central afloramento 01), pedreiras Maringá afloramento 02), Cesbe afloramento 05) e Greca afloramento 13) - ver figura 4 - bem como afloramentos isolados.

O padrão conjugado gerado pelas famílias N-S, NW/SE e NE/SW é bem evidenciado, principalmente, na pedreira Central, conforme mostra a figura 8 e está de acordo com os modelos de fraturamento de Ruhland (op. cit). O mesmo padrão ocorre em outros locais na pedreira e, inclusive, nos demais afloramentos, com padrões típico de fraturas de cisalhamento.

Além dos diques de diabásio o sistema transcorrente também provoca fraturas e rejeitos em corpos intrusivos alcalinos de médio porte (lamprófiros), assim como estrias de atrito e sulcos profundos em gnaisses e migmatitos (Fig. 9). Em afloramentos onde há o contato das rochas do Complexo Atuba e os sedimentos da Formação Guabirotuba, verificou-se que estruturas sub-verticais nos gnaisse se estendem na cobertura sedimentar, com planos de atitudes N10E/70NW, N20W/70NW, N31W/83NE.

Além do sistema transcorrente antes descrito foram observadas outras três tendências nos conjuntos 


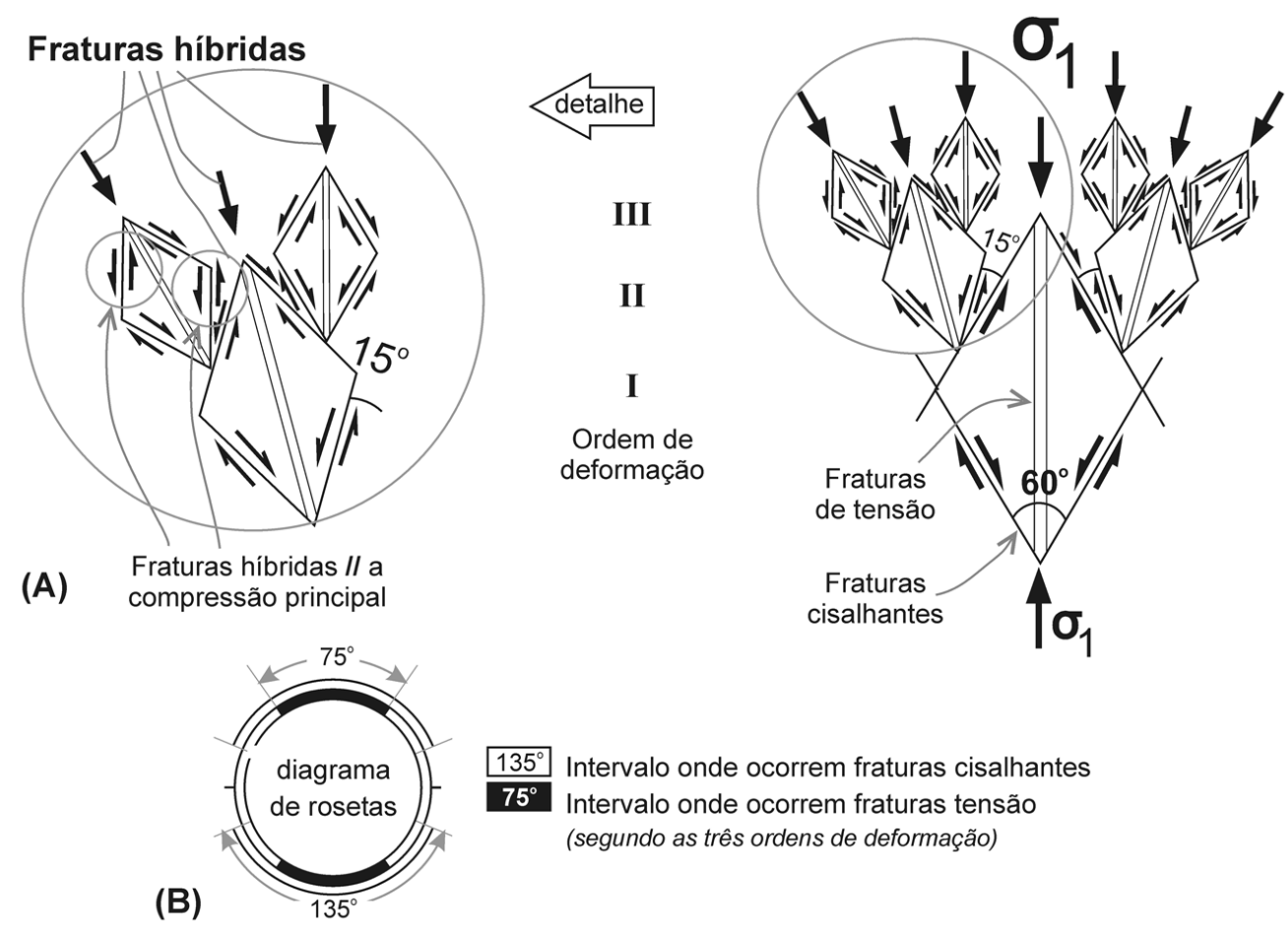

Figura 6 - Arranjo dos planos estruturais tendo como base o modelo de Ruhland (1973). (A) Planos das fraturas de $1^{\circ}, 2^{\circ}$ e $3^{\circ}$ ordens e (B) diagrama de rosetas com $o$ intervalo de ocorrência das fraturas cisalhantes e de tensão.

de estruturas conforme a seguinte ordem de importância: (a) falhas no intervalo N45-65E com mergulhos sub-verticais SE ou NW, com planos em geral estriados e preenchidas por epidoto e/ou ultracataclasito. Em escala regional, pela fotointerpretação, constata-se que as estruturas NE-SW coincidem com alinhamentos antigos do Proterozóico, ou seja, é provável ter havido reativação recente de tais estruturas, por exemplo, Sistema Lancinha (ver Fiori, 1985) com deslocamento lateral e oblíquo; (b) tendência de direção em torno de N60W, caracterizado por planos mais fechados e preenchidos do que as estruturas NE/SW. Nesta direção também foram vistas fraturas com atitude média de N60W/80SW nos sedimentos da Formação Guabirotuba (Bacia de Curitiba); (c) estruturas de grande porte (falhas e fraturas fechadas), proeminentes, de direção E-W, principalmente na região noroeste do município, por vezes com planos oblíquos de até $50^{\circ}$. Neste conjunto de estruturas foram observadas falhas normais e planos transcorrentes, por sua vez, truncados pelo sistema N-S.

No geral os planos das falhas transcorrentes variam em campo desde pequenas estruturas, até zonas de cisalhamento decamétricas. Na observação mais abrangente, por meio de imagens digitais, verifica-se que as estruturas relacionadas ao sistema dominante atingem extensões quilométricas. Outra característica marcante é que as falhas transcorrentes apresentam, freqüentemente, componente de rejeito oblíquo - as estrias de atrito nem sempre são horizontais - podendo ser descritas, portanto, como transcorrentes inversas ou normais.
Em geral os planos mais empinados e com estrias horizontais são mais homogêneos, enquanto que os planos das falhas transcorrentes (NW ou NE) menos empinados e com estrias oblíquas, formam um padrão amendoado ou rede entrelaçada e mais complexa, responsável pelos efeitos de sobreposição e crescimento lateral das fraturas. Algumas estruturas em flor foram identificadas, tendo os indicadores cinemáticos (sigmóides) e estruturas do tipo steps sugerindo padrão transtrativo, posto que a maior parte das falhas transcorrentes observadas apresenta componente normal.

Além do sistema transcorrente, também ocorrem dois conjuntos distintos de estruturas sub-horizontais freqüentemente abertas: (a) juntas tectônicas com superfícies planares penetrativas e continuidade lateral; (b) grandes descontinuidades de baixo mergulho $\left(20^{\circ}\right.$ a $30^{\circ}$ ) formando pares conjugados em forma de $\mathrm{X}$ ou, então, ocorrendo de forma isolada. Este último sistema caracteriza-se por falhas inversas nas direções próximas a N20W/35NE e N20E/20NW e caracterizam-se por apresentar cisalhamento rúptil intenso, inclusive com formação de brecha cataclástica nos gnaisses e deslocamentos em diques de diabásio. As estruturas sub-horizontais (do tipo "a" e "b") foram observadas tanto a norte quanto a sul na área de estudo (por exemplo: afloramentos no CIC e pedreira Marc). As zonas de cisalhamento rúptil de baixo ângulo estão seccionadas pelas falhas de direções NE/SW e NW/SE associadas ao sistema transcorrente. Com base na intersecção entre estruturas sub-horizontais de grande porte e os diques 

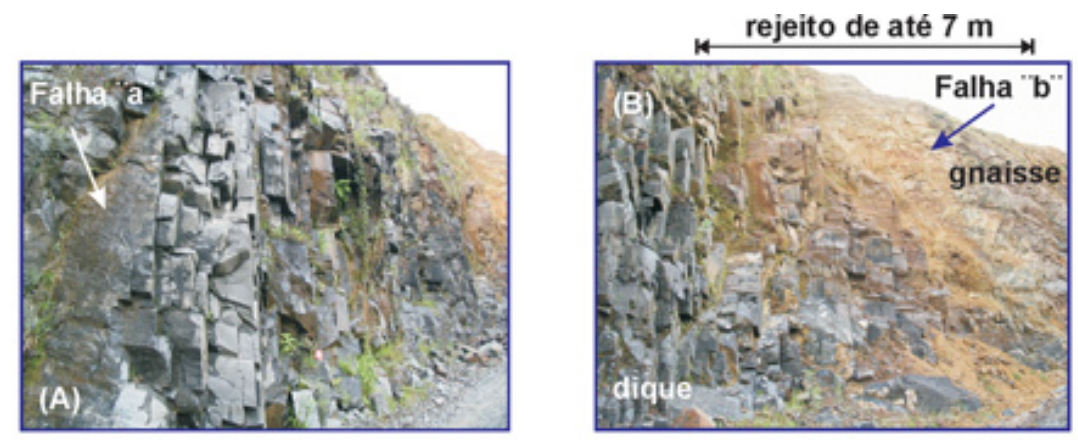

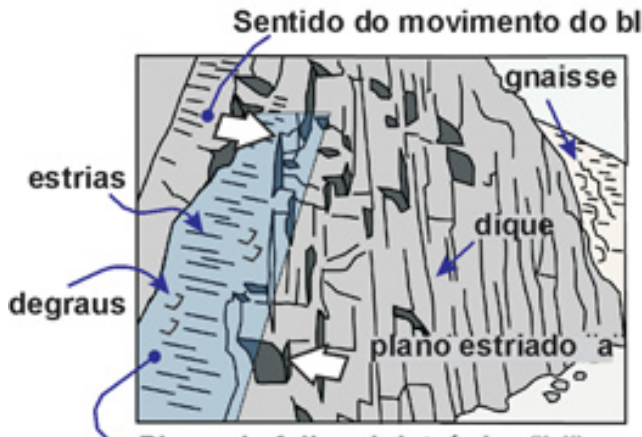

Plano de falha sinistrógira ("a"): N40E/70NW - N35/9

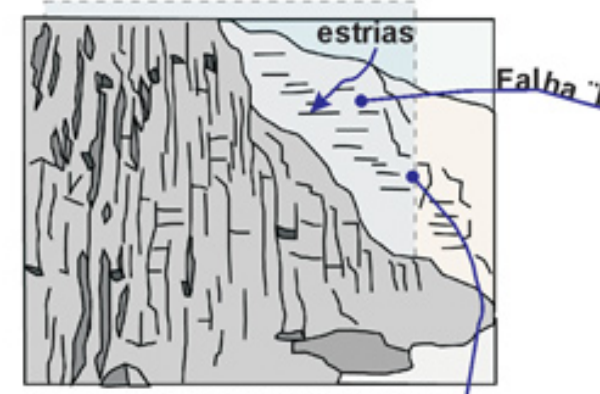

Plano de falha sinistrógira $\left(\mathrm{b}^{-}\right)$: N45E/89NW - N50/11

Figura 7 - Planos transcorrentes são responsáveis pelo cisalhamento rúptil intenso nos gnaisses do Complexo Atuba e corpos intrusivos (A) e (B) Falhas sinistrógiras NE/SW que deslocam o dique de diabásio e produzem rejeito de até $7 \mathrm{~m}$ de largura e (c) Vista em planta da lavra da pedreira Inecol (Afloramento 03).

Falha N-S e fraturas de extensão (híbridas)

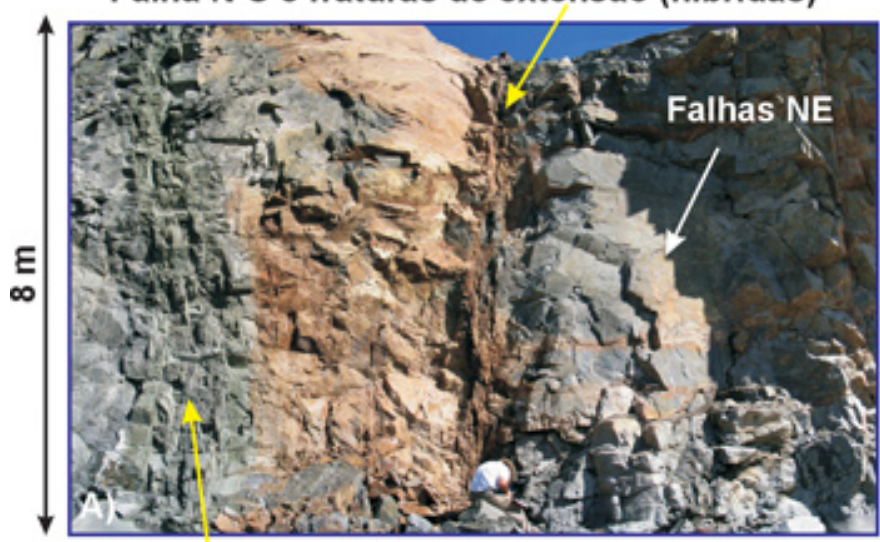

Zona cisalhamento NW (transcorrentes dextrógiras) que desloca dique de lamprófiro e de diabásio

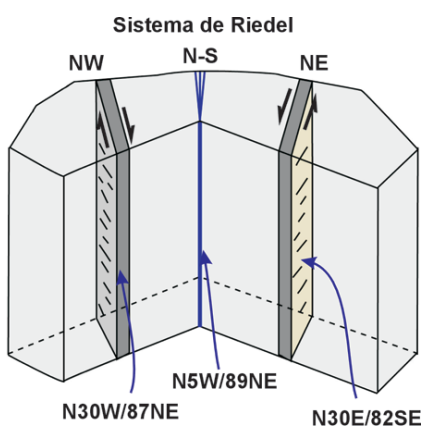

B)

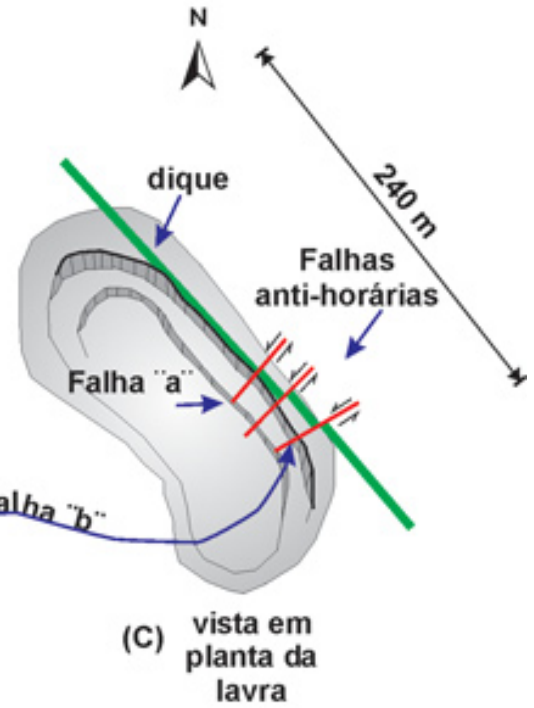

Figura 8 - Familias N-S, NW/SE e NE/SW, seguem modelo de Riedel (pedreira Central, ponto 01).

de diabásio e lamprófiro, bem como a intersecção entre os planos sub-horizontais e os planos de falhas com mergulhos sub-verticais, a cronologia de eventos entre as diferentes famílias de fraturas e/ou estruturas foi interpretada na seguinte ordem de ocorrência: (a) diques; (b) falhas inversas e juntas de baixo ângulo e (c) falhas transcorrentes, sub-verticais e oblíquas.
DETERMINAÇÃO DAS TENSÕES PRINCI-

PAIS O reconhecimento espacial das tensões principais, responsáveis pelo condicionamento das estruturas recentes que seccionam as rochas do Complexo Atuba é fundamental para a determinação da tectônica rúptil desta unidade.

As principais características estruturais decorrem do sistema transcorrente e para representar a trama 


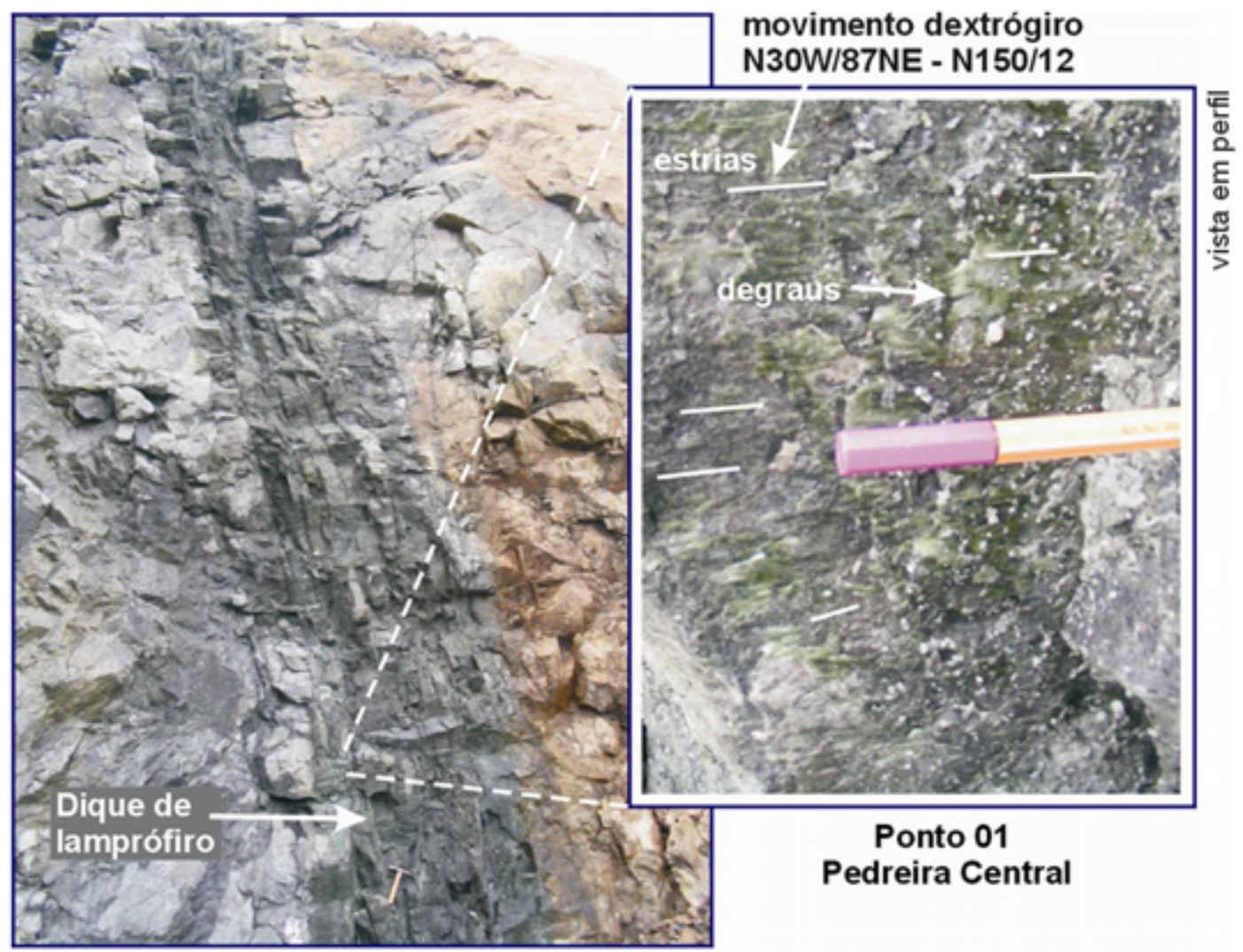

\begin{abstract}
Figura 9 - Zona de falhas transcorrentes com cinemática dextrógira que cortam dique de lamprófiro (afloramento 01 - Pedreira central).
\end{abstract}

observada nos planos de fraturas e falhas utiliza-se dos modelos teóricos de cisalhamento rúptil. Assim, de início são discutidos aspectos relativos a possíveis ajustes do campo de esforços e características dos planos ajustadas aos modelos estruturais existentes. Na seqüência, a partir da análise cinemática fez-se correlação espacial das estruturas associadas ao sistema transcorrente, com ajustes das estruturas segundo os esforços tectônicos atuantes no campo de tensão mais recente.

Os dados estruturais observados nas rochas do Complexo Atuba permitiram a construção de estereogramas com auxílio do programa STEREONETT v 2.4, com o objetivo de definir espacialmente o provável ajuste do campo de tensão mais recente. Para tanto foram empregados os métodos de Turner (1953) e Angelier e Mechler (1977) que utilizam os indicadores cinemáticos de falhas como base para as análises. Além destes, com os dados obtidos na pedreira Central, onde ocorre o afloramento típico que retrata com mais precisão o processo tectônico aqui abordado, foi realizada a análise, de forma manual, pelo método de Arthaud (1969). Nos cálculos realizados se utilizou apenas as informações referentes aos planos sistemáticos das falhas transcorrentes recentes ou reativadas a partir do Neógeno.

As estruturas relacionadas às falhas transcorrentes consideradas como integrantes de um mesmo sistema, portanto passíveis do emprego na solução dos tensores, foram preferencialmente aquelas contidas no intervalo entre N40W a N40E. As estruturas com características muito discordantes dos padrões gerais observados (medidas incertas, planos com mergulho menores de $70^{\circ}$ ou falhas com estrias de atrito com obliquidade acima de $30^{\circ}$ ), em um primeiro momento foram consideradas, mas verificou-se que estão fora do padrão estatístico e foram desconsideradas, na busca da homogeneização das informações, pois medidas anormais tomadas em ondulações de espelhos de falhas falseiam as interpretações (ver discussão em Torres, 1994). Direções dos planos de falhas próximas a E-W não foram utilizadas, pois são estruturas mais antigas, portanto truncadas pelas estruturas em análise, e assim sendo não foram objeto de consideração. Isto se deve ao fato de que esta família se relaciona ao campo de tensão E-W gerado em evento tectônico anterior ligado ao movimento lateral da placa Sul-americana. Na seqüência são apresentados os estereogramas obtidos para os campos de tensão associados somente às falhas transcorrentes, cuja representação obedeceu aos três métodos de análise cinemática. A figura 10 representa as posições obtidas segundo o modelo teórico de Angelier e Mechler (op. cit.) quando as tensões principais atuam na situação de transcorrência. Nos estereogramas obtidos na área de estudo estas áreas de compressão podem ser observadas, de forma semelhante ao esquema apresentado. A simbologia geral utilizada para representar a posição dos tensores conforme o método de Turner é 


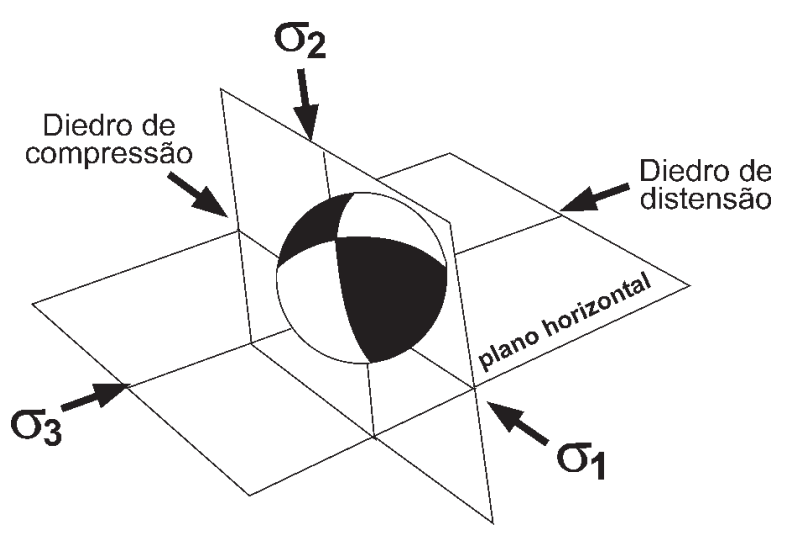

Figura 10 - Diedros compressivos e distensivos para falhas transcorrentes segundo o método de Angelier e Mechler (op. cit.).

mostrado na figura 11.

Pelo método dos diedros retos de Angelier e Mechler (op cit.) Os esforços são representados por isolinhas dos pólos em tons de cinza, onde os diedros compressivos apresentam cor escura e os diedros distensionais correspondem às porções claras (Fig. 11).

No método de Turner (1953) São plotados símbolos que representam a posição dos tensores principais (ortogonais entre si). Os símbolos empregados estão representados na legenda da figura 11. A base para este método é a suposição que estruturas paralelas a $\sigma_{2}$ são originadas com um ângulo de cerca de $30^{\circ}$ para $\sigma_{2}$.

Determinação das direções principais de tensão segundo o método de Arthaud (op. cit.) Os dados da pedreira Central foram separados em dois conjuntos distintos de falhas transcorrentes: (a) 70 atitudes de planos e estrias com componente de deslocamento normal; (b) 50 planos e estrias com componente de deslocamento inverso (Fig. 12). Na seqüência, com auxílio do diagrama de Schmidt-Lambert, para cada conjunto foram marcados os pólos das estruturas e as estrias respectivas. Fazendo-se coincidir os pares em um mesmo meridiano, foram plotados individualmente os chamados "pólos virtuais" (PV). A orientação preferencial destes pontos define uma guirlanda que, por sua vez, representa um dos planos que contém duas das três direções principais de deformação (Fig. 12B). Como o procedimento foi feito de forma separada para as falhas transcorrentes normais e inversas, deu-se origem a dois planos médios, cuja intersecção definiu o tensor médio $\sigma_{2}$ (vertical). Com base neste sistema triaxial (os dois planos médios e o ponto de intersecção) foi traçado a $90^{\circ}$, a partir de $\sigma_{2}$ uma terceira guirlanda (chamado de plano auxiliar), possibilitando determinar a posição dos outros dois tensores. Na figura $12 \mathrm{C}$, o tensor $\sigma_{3}$ é o ponto de intersecção próximo à área onde ocorrem preferencialmente as estrias normais, ao contrário de $\sigma_{1,}$ que ocorre junto a maior concentração de estrias inversas

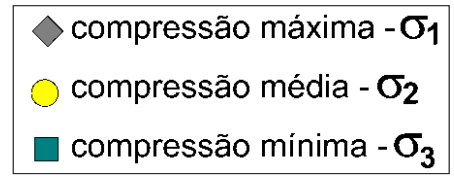

Figura 11 - Símbolos que representam as tensões principais de acordo com o método de Turner (op. cit.).

(área de compressão).

Os estereogramas com a solução dos tensores foram confeccionados individualmente para os afloramentos que apresentaram dados suficientes do conjunto de estruturas planares e lineares - estrias de falhas para permitir as análises afloramento 1 até o ponto 9). Os ajustes obtidos podem ser vistos nas figuras 13 a 21.

A localização das pedreiras analisados poder ser visualizada na figura 04 (afloramentos 1 - Pedreira Central, 2 - Pedreira Maringá, 3 - Pedreira Inecol, 4 Pedreira Pussoli, 5 - Pedreira Cesbe, 6 - Pedreira Transembra, 7 - Cascatinha, 8 - Parque Tanguá 9 - CIC).

Os dados estruturais dos planos de falhas transcorrentes, em geral, mostram uma similaridade quanto ao ajuste da compressão máxima e mínima, principalmente ao se aplicar o método de Turner (op. cit). Já os resultados obtidos aplicando-se o método dos diedros retos, mostraram variações em alguns afloramentos, a exemplo dos estereogramas confeccionados para os afloramentos 02 (pedreira Maringá), 03 (pedreira Inecol) e 08 (parque Tanguá). A visão integrada dos estereogramas (método de Turner) pode ser vista na figura 22. Pelo método de Turner (op. cit) $\sigma_{1}$ mostra um ajuste geral a N-S, ao contrário do que acontece por meio do método dos diedros retos. O número limitado de dados na direção NW/SE ou a NE/SW pode ser o responsável pela variação nos cálculos, já que quanto maior é a quantidade de medidas de falhas e estrias, mais restritas são as regiões de ocorrência dos eixos dos tensores, melhorando a precisão do resultado final.

Embora haja uma pequena variação para os quadrantes NW ou NE em alguns afloramentos, os dados obtidos nas várias pedreiras onde aflora o Complexo Atuba, considerados como afloramentos chaves, por exemplo, na pedreira Central afloramento 01), confirmam uma característica já detectada antes por ChavezKus (2003): os planos de falhas e relações geométricas dos indicadores cinemáticos indicam uma direção N-S para a compressão da tensão principal $\sigma_{1}$.

De acordo com os resultados da análise geométrica e cinemática, o ajuste que melhor se adapta ao modelo de Riedel (op. cit), indica um binário com movimentação sinistrógira (Fig. 23A) onde o vetor de tensão máxima $\left(\sigma_{1}\right)$ está posicionado na horizontal e orientado para N-S, a tensão principal mínima $\left(\sigma_{3}\right)$ está orientado na direção E-W enquanto que a tensão principal média $\left(\sigma_{2}\right)$ está aplicado na vertical. Nesta situação as dire- 


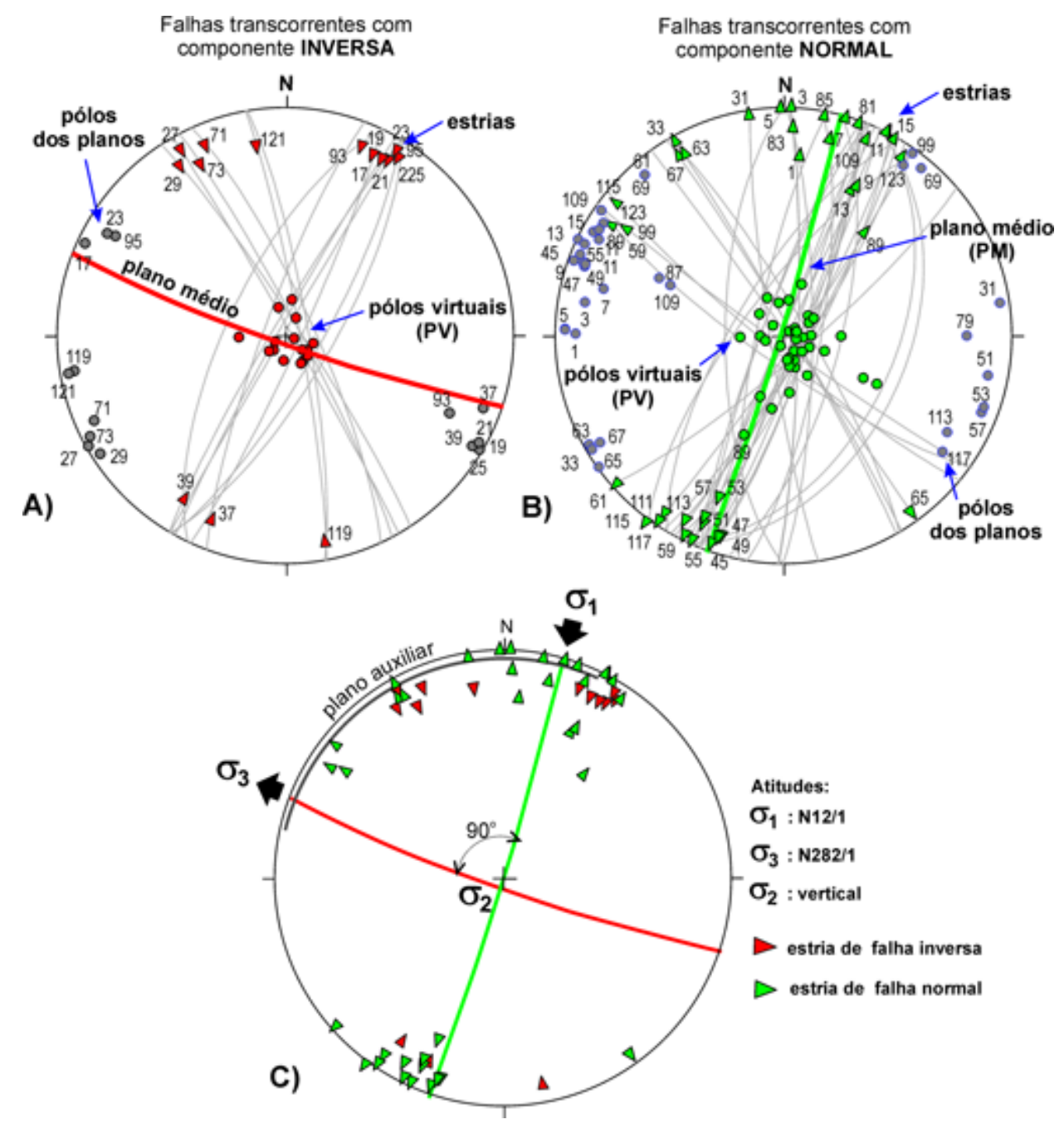

Figura 12 - Solução das tensões principais para a pedreira Central, segundo o método de Arthaud (op. cit.). (A) Falhas transcorrentes com componente normal: pólos dos planos e as estrias respectivas junto com o traçado dos pólos virtuais (PV) e plano médio (PM); (B) Pólos dos planos com as estrias das falhas transcorrentes inversas, assim como determinação dos PV e PM; (C) Solução final.

ções dos planos de falhas transcorrentes N20-30E correspondem às fraturas de cisalhamento $\mathrm{R}$ (de Riedel), a direção N-S coincide com as fraturas de partição (T) e os planos N20-30W são equivalentes às fraturas cisalhamentos R'. Já as estruturas no intervalo N45-60E são relacionadas aos planos $\mathrm{Y}$ e $\mathrm{P}$, falhas antigas reativadas, relacionadas à zona de cisalhamento transcorrente Lancinha-Cubatão (ver Fiori, op. cit; Fassbinder, 1990 e Salamuni, 1995), enquanto que a direção N50$60 \mathrm{~W}$, também a direção dos planos de fraqueza onde os diques de diabásio estão intrudidos, é paralela ao plano $\mathrm{X}$ do modelo (Fig. 23B a 23F).

Como os blocos adjacentes às falhas transcorrentes apresentam componentes oblíquos em sua movimentação, observa-se que nos ajustes obtidos com o método de Turner (op. cit.) o $\sigma_{1}$ apresenta mergulho de até $10^{\circ}$ no sentido a sul ou no sentido norte. As estruturas de direção $\mathrm{N}-\mathrm{S}$ apresentam, com freqüência, deslocamento entre os blocos adjacentes à falha, justificando-se o ajuste propos- to para o campo de tensão pré-atual onde a compressão principal $\left(\sigma_{1}\right)$ é paralela à direção mencionada, posto que zonas de cisalhamento de diferentes idades e direções participam da estruturação de falhas de grande porte do terreno. Além disso, as reativações no campo de tensão induzem ao desenvolvimento de uma série de estruturas secundárias, ocorrendo na região processos de propagação e crescimento lateral (linkage). Em função da interação entre diferentes planos estruturais gerados de acordo com a tensão, e devido a geometria dos mesmos, o movimento dos planos adjacentes em parte é transferido às fraturas de tensão ("T").

DISCUSSÃO E CONCLUSÃO Pelo exposto, conclui-se que há um importante evento tectônico, provavelmente no Neógeno, ligado a uma compressão da crosta na direção N-S. A deformação envolvida confirma e aprofunda a conclusão de Salamuni (1998) e Salamuni et al. (2003), da existência de um evento de deformação, 


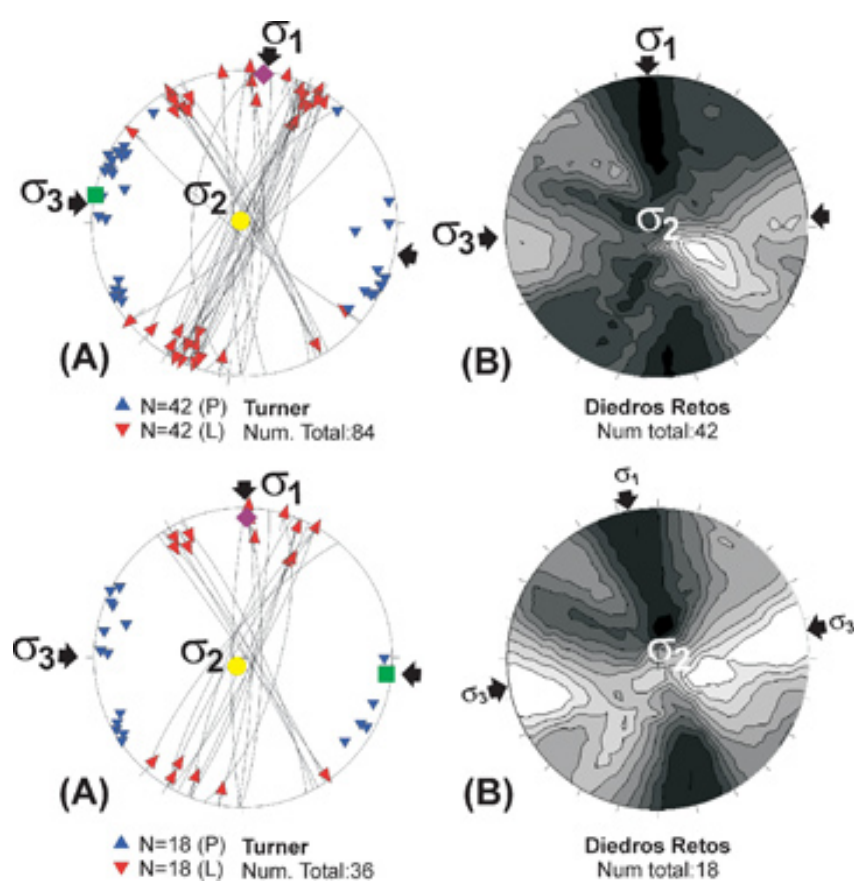

Figura 13 - Construção de estereogramas com base nos métodos de Turner (1953) e Angelier \& Mechler (1977) com o objetivo de definir espacialmente o provável ajuste do campo de tensão mais recente. (A) Determinação das tensões principais para a pedreira Central com 42 atitudes de falhas e estrias; (B) Solução com 18 atitudes.
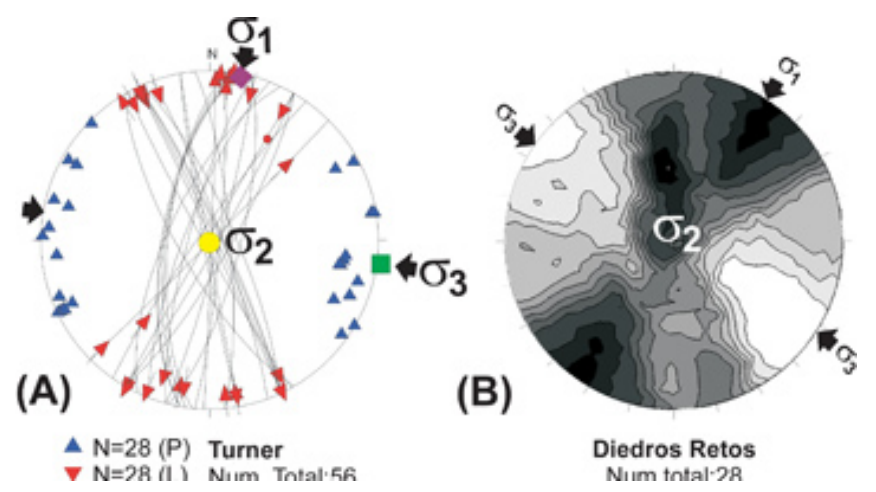

Figura 14 - Determinação das tensões principais para a pedreira Maringá.
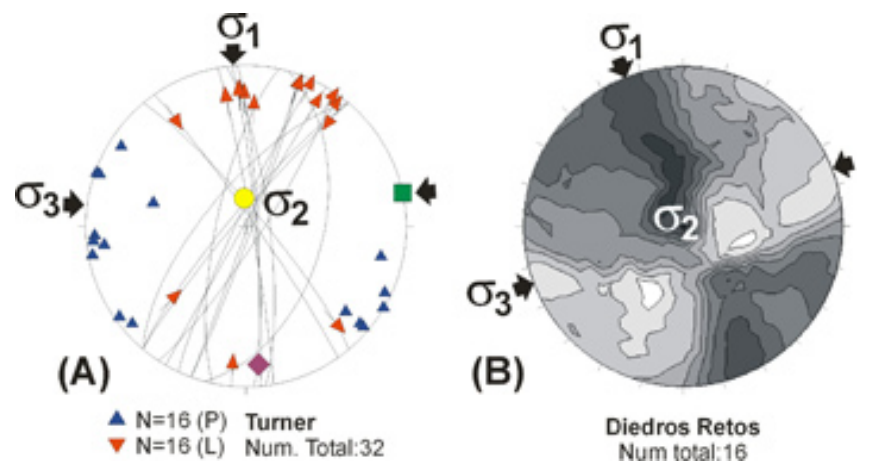

Figura 15 - Determinação das tensões principais para a pedreira Inecol.

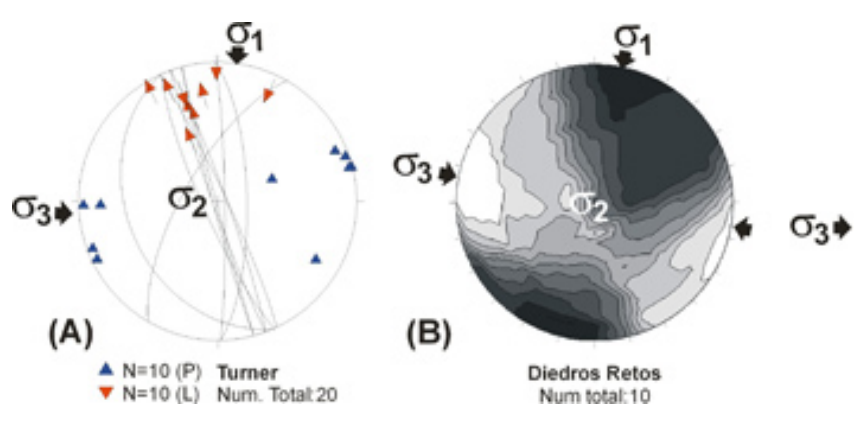

Figura 16 - Determinação das tensões principais para a pedreira Pussoli.

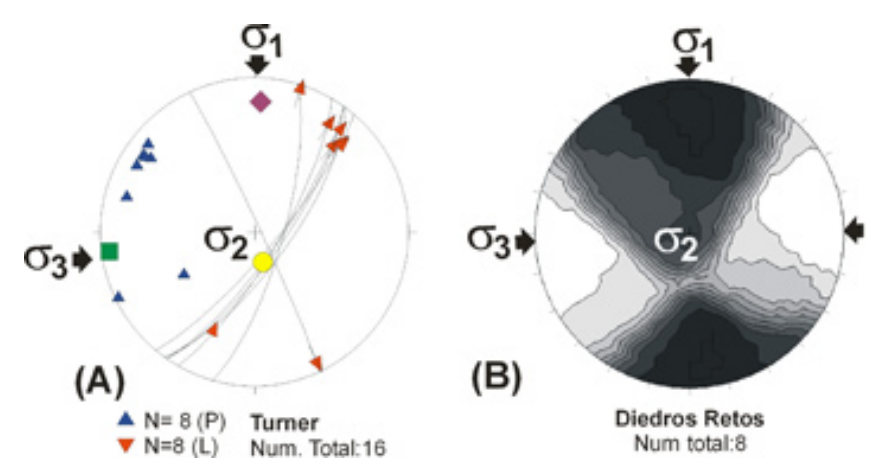

Figura 17 - Determinação das tensões principais para a pedreira Cesbe.

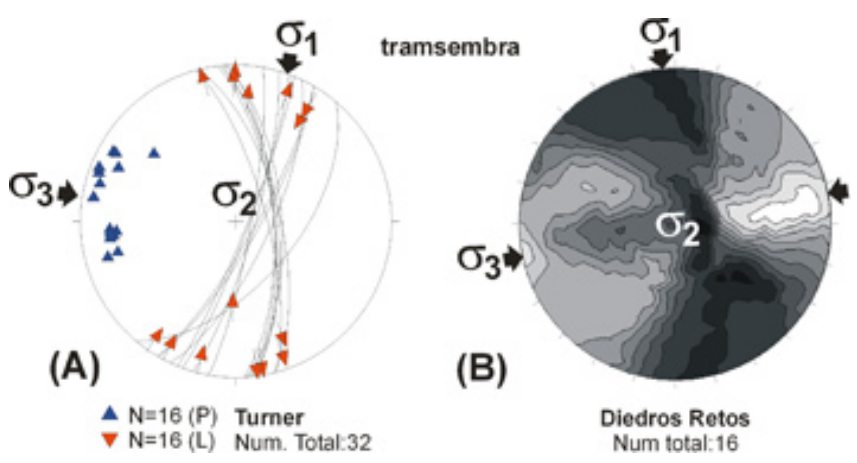

Figura 18 - Determinação das tensões principais para a Pedreira Transembra.

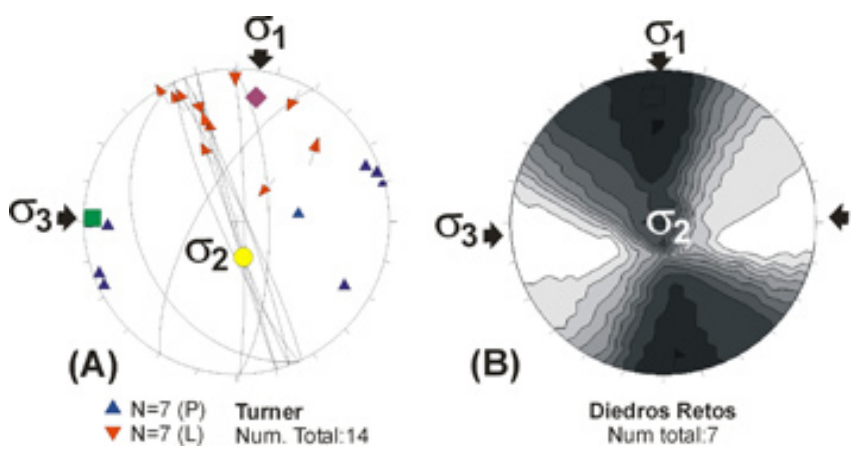

Figura 19 - Determinação das tensões principais para a afloramento atrás do restaurante Cascatinha. 


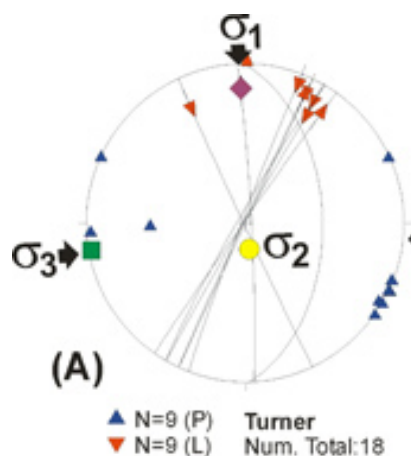

Figura 20 - Determinação das tensões principais para a pedreira do parque Tanguá.

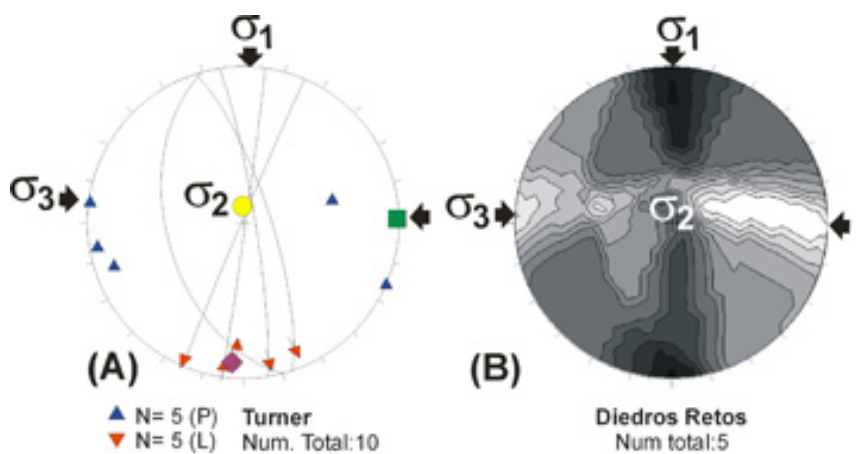

Figura 21 - Determinação das tensões principais para o afloramento no corte de estrada da Av. Juscelino K. de Oliveira no bairro do CIC.

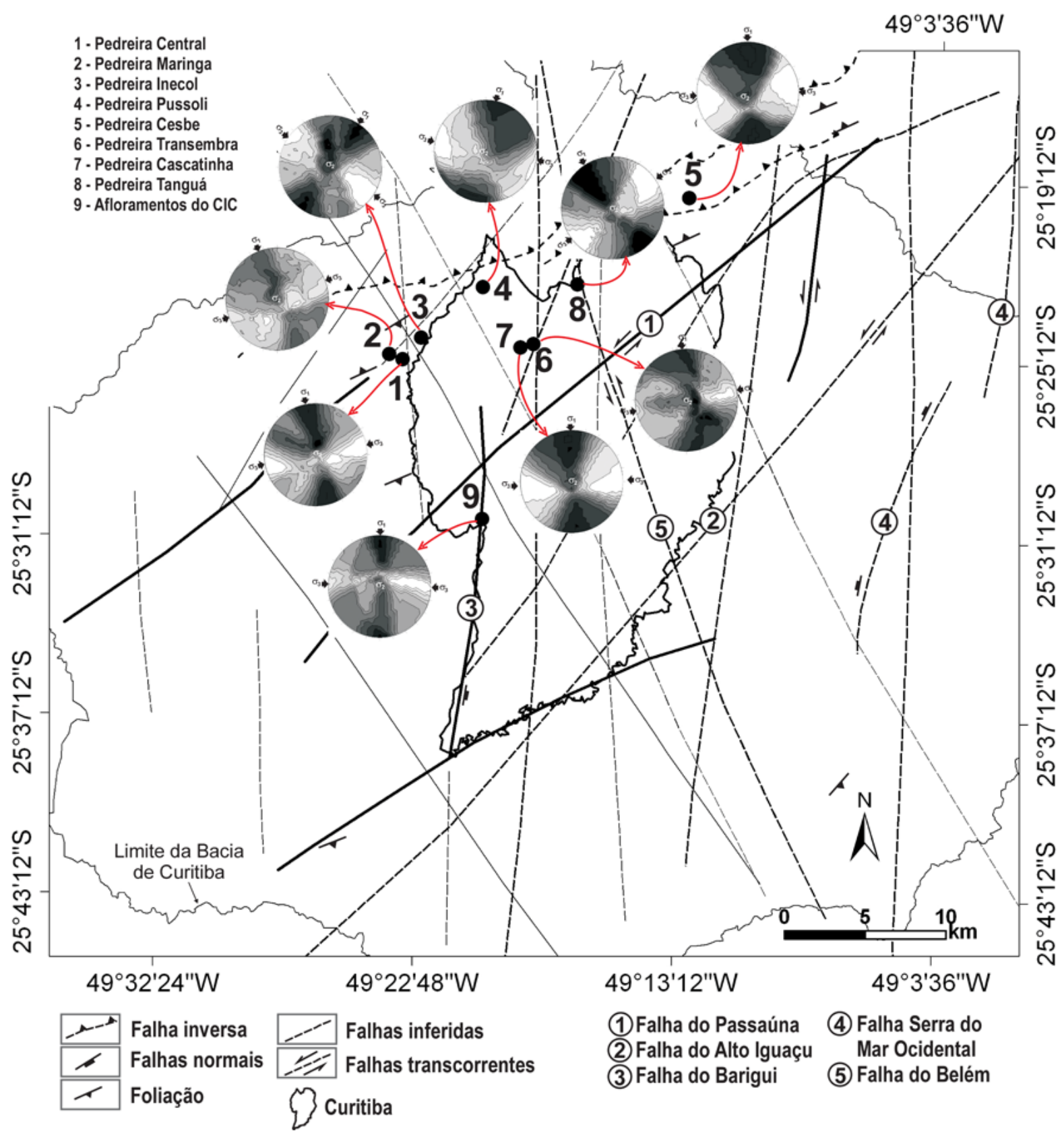

Figura 22 - Mapa de localização da área de estudo com a visao integrada dos estereogramas obtidos na análise cinemática. 
(A)

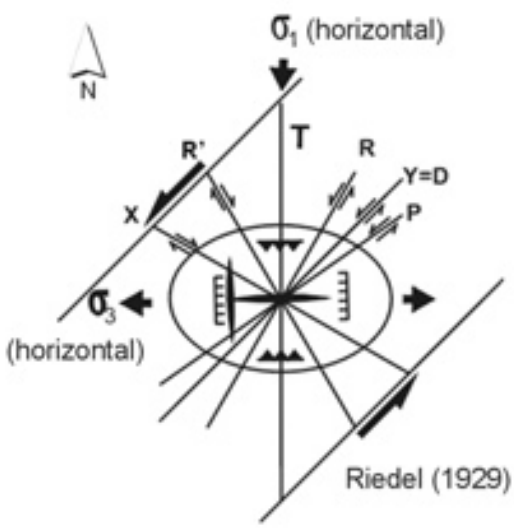

(C)

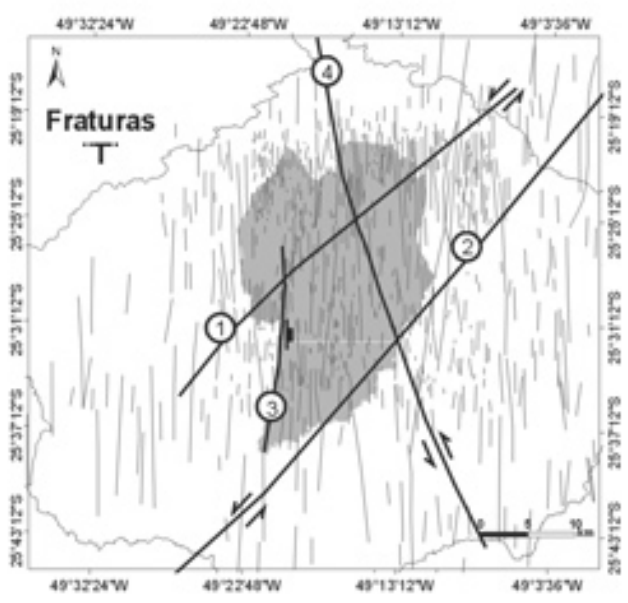

(E)

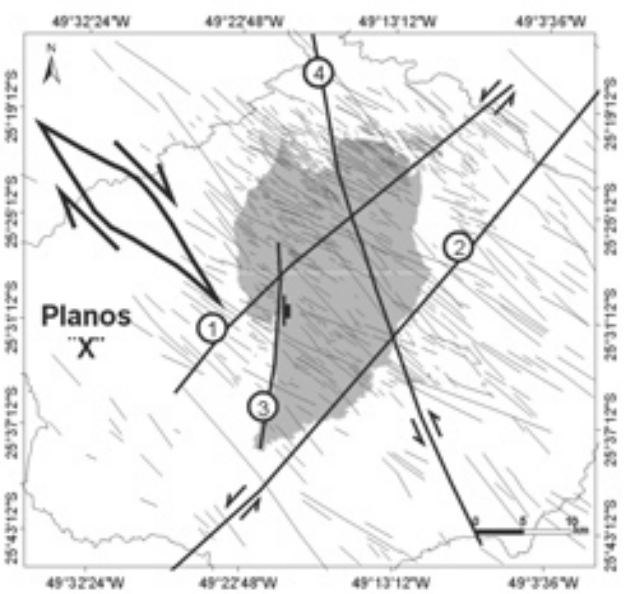

(B)

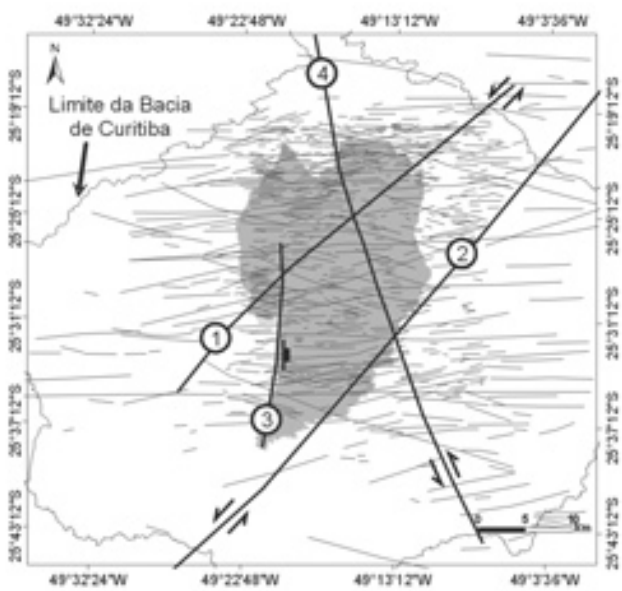

(D)
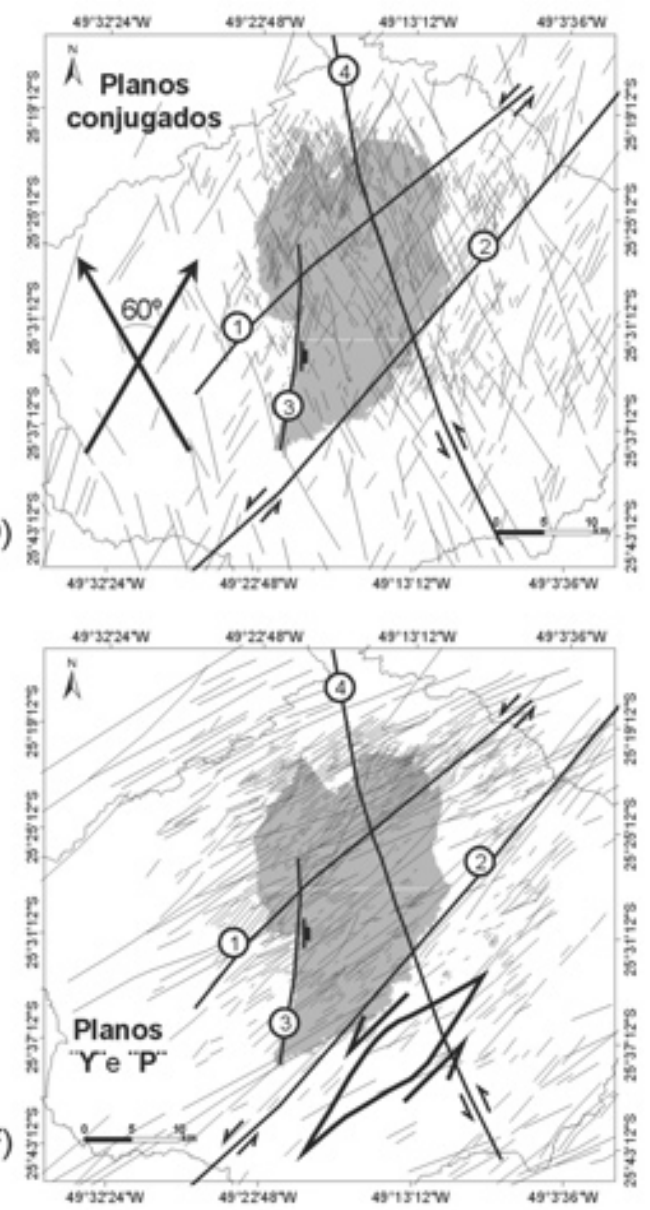

feiçăo sigmoidal
Limite da Bacia de Curitiba Municipio de Curitiba (em cinza)

Figura 23 - Visão integrada do ajuste que melhor se adapta ao modelo de Riedel e planos estruturais de maior significado na região de Curitiba. (A) Ajuste do campo de tensão mais recente com base na análise estrutural das falhas trancorrentes associadas ao sistema $N-S$ do Complexo Atuba; (B) Lineamentos de relevo nas direções N70-90W e N70-90E; (C) Planos próximos a N-S (fraturas "T"); (D) Planos conjugados próximos a N30W e N30E (planos conjugados); (E) Lineamentos próximos a N50W (planos " $X$ "); (F) Lineamentos próximos a N45-60E (planos " $Y " e$ " $P "$ "): são aqueles que coincidem com a mesma direção da zona de cisalhamento transcorrente Lancinha-Cubatão. Os planos foram identificados com base no modelo de Riedel (1929). 
no qual o $\sigma_{1}$ está direcionado a N-S, cíclico em relação ao padrão tectônico esperado para as tensões principais da Placa Sul-americana, posicionadas na direção aproximada E-W (evento D2 - transpressional - de Salamuni, 1998).

As falhas inversas de grande porte e mergulhos baixos, também responsáveis pelo deslocamento dos diques seccionados pelas falhas transcorrentes do sistema N-S, encaixam-se no contexto de ciclo tectônico intermediário entre os eventos D2 (Fig. 2A e 2B) e D2' (Fig. 3A e 3B), atribuído por Salamuni (1998) a uma tectônica compressiva, devido a uma progressividade da tectônica em função de uma possível rotação de placas continentais.

O posicionamento proposto para o campo de tensão atual ou pré-atual - tensão principal $\sigma_{1}$ posicionada na direção N-S, cujo ajuste coincide com a fase D2' de Salamuni (op. cit), binário sinistrógiro (Fig. 3B) - insere no modelo geral que propõe uma tensão compressional E-W em quase a totalidade da Placa Sul-americana, a possibilidade de haver ciclos em que a atuação da tensão principal deixa de ser E-W, e passa a estar em outras direções, mesmo que em blocos tectônicos restritos dentro da placa. Esta tectônica provocou descontinuidades estruturais importantes no Complexo Atuba, gerando falhas transcorrentes, cuja extensão varia de metros a quilômetros, criando zonas de cisalhamento rúptil, por vezes, de mais de uma dezena de metros.

Esta configuração, por constituir uma tectônica diferente do que vem se definindo sobre as tensões intraplaca da Placa Sul-americana, deve ser investigado também em outros domínios estruturais da placa, posto que há possibilidade concreta de se encontrar deformações compatíveis com este quadro tectônico, tais como grandes falhas com direção N-S e reativações de sistemas de falhas, como no caso do sistema transcorrente LancinhaCubatão, no cinturão de cisalhamento Ribeira.

Agradecimentos Este trabalho recebeu o apoio financeiro da Fundação Coordenação de Aperfeiçoamento de Pessoal de Nível Superior - CAPES (bolsa de doutorado no Brasil e Bolsa de Estágio de Doutorando no Exterior / Processo 1897047, primeiro autor). Aos revisores da RBG pelas sugestões ao manuscrito.

\section{Referências}

Angelier J. \& Mechler P. 1977. Sur une méthode graphique de res. des contraintes principales également. Bulletin de la Societé Geologique de France, p.1309-1318.

Arthaud F. 1969. Methode de determination graphique des directions de reccourcissement d'allongement et intermediare d'une population de failhes. Bulletin de la Societe Geologique de France, 7(11):729-737.

Assumpção M. 1992. The Regional Intraplate Stress Field in South America. J. Geophys. Res., 97(B8):11.88911.903.

Basei M.A.S., Siga Jr. O., Machiavelli A., Mancini F. 1992. Evolução tectônica dos terrenos entre os cinturões Ribeira e Dom Feliciano (PR-SC). Rev. Bras. Geoc., 22(2):212-227.

Batola J.R., F., Silva A.T.S.F., Algarte J.P. 1981. O pré-cambriano da região sul-sudeste do Estado de São Paulo e leste-nordeste de Estado do Paraná. In: SBG, Simpósio regional de Geologia, 3., Curitiba, Atas, p.94-108.

Bigarella J.J. \& Salamuni R. 1959. Notas complementares à planta geológica da cidade de Curitiba e arredores. Bol. do Inst. de Biologia e Pesquisas Tecnológicas, 40:1-14.

Bilham R. \& King G. 1989. The morphology of strike -slip faults: examples from the San Andreas fault, California. J. Geophys. Res., 94:10204-10216.

Burbank D. W. \& Anderson R.S. 2001. Tectonic Geomorphology. USA, Blackwell Science, p. 274.

Fassbinder E. 1990. Análise estrutural da Falha da Lancinha - Estado do Paraná. Dissertação de Mestrado. IG-USP, São Paulo, 165p.

Fiori A.P. 1985. A falha da Lancinha no pré-cambriano paranaense: reflexo de uma falha profunda. Boletim Paranaense de Geociências, 39:3-14.

Fuck R., Trein E., Marini O.J. 1967. Geologia e petrografia dos migmatitos do Paraná. Bol. Paranaense Geoc., 23/25:5-41.
Gamond J.F. 1983. Displacement features associated with fault zones: a comparison between observed examples and experimental models. J. Struct. Geol., 5:3345- a ?

Hasui Y. 1990. Neotectônica e tectônica ressurgente no Brasil. Boletim do Núcleo de Minas Gerais da Sociedade Brasileira de Geologia, Belo Horizonte, 9:1-34.

Kim Y-S, Andrews Jr, Sanderson D.J. 2001. Reactivated strike-slip faults: examples from north Cornwall, UK". Tectonophysics, 340:173-194.

Lima C.C. 1999. Inversão Nascente de Bacias: expressões topográficas e estruturais e implicações. In: SBG, Simp. Nac. Est.Tect., Lençóis, atas, 4:29-30.

Mcgrath A.G. \& Davison I. 1995. Damage zone geometry around fault tips. J. Struct. Geol. 17:1011 -1024.

Moody J.D. \& Hill M.J. 1956. Wrench fault tectonics. Geol. Soc. Am. Bull., 67:1207-1246.

Petit J.P. 1987. Criteria for the sense of movement on fault surfaces in brittle rocks: J. Struct. Geol., 9:597-608.

Price N.J. 1968. A dynamic mechanism for the development of second order faults. In: Baer A. J.E., Norris D.K. (eds.) Proceedings of the Conference on Research in Tectonics. Geological Survey of Canada, p.52-68.

Price N.J. \& Cosgrove J.W. 1990. Analysis of Geological Structures. London, Cambridge Univ. Press, 502p.

Riccomini C. 1989. O Rift Continental do Sudeste do Brasil. Tese de Doutoramento, Instituto de Geociências, Universidade de São Paulo, São Paulo, 256p.

Riccomini C. 1995. Tectonismo gerador e deformador dos depósitos sedimentares pós-gondvânicos da porção centro-oriental do Estado de São Paulo e áreas vizinhas. Tese de Livre-docência, Instituto de Geociências, Universidade de São Paulo, São Paulo, 100p.

Riccomini C. 1997. Arcabouço estrutural e aspectos do tectonismo gerador e deformador da Bacia Bauru no Estado de São Paulo. Revista Brasileira de Geociências, 
27(2):153-162.

Riccomini C. \& Assumpção M. 1999. Quaternary tectonics in Brazil. Episodes, 22(3):221-225.

Riedel W. 1929. Zur mechanik geologischer brucherscheinungen. Ein beitrag zum problem der fiederspalten. Zentralblat fur Mineralogie, Verlagsbuchhandlung, 1919b:354-368.

Ruhland M. 1973. Méthode d'étude de la fracturation naturelle des roches associées à divers modèles structuraux. Bull. Sci. Geol. Strasbourg, 26:91-113.

Salamuni E. 1995. Dobramentos e redobramentos na porção sul da Zona de Cisalhamento Lancinha-Cubatão. Boletim Paranaense de Geociências, 43:135-139.

Salamuni E. 1998. Tectônica da Bacia Sedimentar de Curitiba (PR). Tese de Doutoramento, Inst. Geoc. e Ciências Exatas, UNESP, Rio Claro (SP), 214p.

Salamuni E., Ebert H.D., Borges M.S., Hasui Y., Costa J.B.S., Salamuni R. 2003. Tectonics and sedimentation of the Curitiba Basin. Journal of South American Earth Sciences, EUA, 15(8):901-910.

Salamuni E., Ebert H. D., Hasui Y. 2004. Morfotectônica da Bacia Sedimentar de Curitiba. Rev. Bras. Geoc., 34(4):469-478.

Sanderson D.J. \& Marchini W.R.D. 1984. Transpression. J. Struct. Geol., 6:449-458.

Schreurs G. \& Colletta B. 1998. Analogue modelling of faulting in zones of continental and transtension. In: Holdsworth R.E., Strachan R.A., Dewey J.F. (eds.) Continental Transpressional and Transtensional Tectonics. Geol. Soc. London, Spec. Publ., 135:59-79.

Siga Júnior O., Basei M.A.S., Reis Neto J.M., Machiavelli A., Harara O.M. 1995. O Complexo Atuba: um cinturão Paleoproterozóico intensamente retrabalhado no Neoproterozóico. Boletim IG-USP Série Científica, 26:69-
98.

Singhal B.B.S. \& Ravi P.G. 1999. Applied Hydrogeology of Fractured Rocks. Dordrecht: Kluwer Academic Publishers, $400 \mathrm{p}$.

Stefanick M. \& Jurdy D.M. 1992. Stress observations and driving force models for the South American Plate. Journal of Geophysical Research, 97(B8):11905-11913.

Tchalenko J.S. \& Ambraseys N.N. 1970. Structural analysis of the Dasht-e Bayaz (Iran) earthquake fractures. Bull. geol. Soc. Am, 81:4-60.

Torres H.H.F. 1994. Metodologia para estudo Neotectônicos Regionais: o caso João Câmara. Recife. CPRM, Série Publicações especiais, v.3, 50p.

Turner F.J. 1953. Nature and dynamic interpretation of deformation Iamallae im calcite of three marbles. Am. J. Sci., 251:276-298.

Turner F.J. 1957. Lineation, symmetry and internal movement in monoclinic tectonite fabrics. Geol. Soc. Am. Bull., 68:1-17.

Wilcox R.E., Harding T.P., Seely D.R. 1973. Basin wrench tectonics. Buletin American Association of Petroleum Geologists, 57:74-96.

Willemse E.J.M. \& Pollard D.D. 1998. On the orientation and patterns of wing cracks and solution surfaces at the tips of a sliding flaw or fault. J. Geophys. Res., 103:24272438.

Zoback M.D. 1992. First and second order patterns of stress in lithosphere: the World Stress Map Project. Journal of Geophysical Research, 97:11703-11728.

Manuscrito ID 11105

Submetido em 14 de abril de 2008 Aceito em 20 de setembro de 2008 Sistema eletrônico de submissão 